\title{
Conformation-Specific Spectroscopy of Peptide Fragment lons in a Low-Temperature Ion Trap
}

\author{
Tobias N. Wassermann, ${ }^{1}$ Oleg V. Boyarkin, ${ }^{1}$ Béla Paizs, ${ }^{2}$ Thomas R. Rizzo ${ }^{1}$ \\ ${ }^{1}$ Laboratoire de Chimie Physique Moléculaire, École Polytechnique Fédérale de Lausanne, 1015 Lausanne, Switzerland \\ ${ }^{2}$ Computational Proteomics Group, German Cancer Research Center, 69120 Heidelberg, Germany
}

\begin{abstract}
We have applied conformer-selective infrared-ultraviolet (IR-UV) double-resonance photofragment spectroscopy at low temperatures in an ion trap mass spectrometer for the spectroscopic characterization of peptide fragment ions. We investigate $b$ - and $a$-type ions formed by collisioninduced dissociation from protonated leucine-enkephalin. The vibrational analysis and assignment are supported by nitrogen-15 isotopic substitution of individual amino acid residues and assisted by density functional theory calculations. Under such conditions, $b$-type ions of different size are found to appear exclusively as linear oxazolone structures with protonation on the $\mathrm{N}$ terminus, while a rearrangement reaction is confirmed for the $a_{4}$ ion in which the side chain of the $\mathrm{C}$-terminal phenylalanine residue is transferred to the $\mathrm{N}$-terminal side of the molecule. The vibrational spectra that we present here provide a particularly stringent test for theoretical approaches.
\end{abstract}

Key words: Peptide fragmentation, Cold ion spectroscopy, b- and a-Type fragment ions, Tandem mass spectrometry

\section{Introduction}

$\mathrm{U}$ nderstanding the mechanisms of peptide fragmentation is important [1, 2] for developing more reliable algorithms for the interpretation of peptide product ion spectra. Numerous recent studies indicate that collisioninduced dissociation (CID) can lead to sequence scrambling $[3,4]$ and major structural rearrangements [5, 6]. The relevance of these chemistries for peptide sequencing is a subject of current debate [7, 8]. Characterization of the structures of peptide fragment ions, which are intermediates in the fragmentation process, is crucial for understanding fragmentation and permutation mechanisms.

Different tools, sometimes in combination, have been applied for obtaining information on the structures of

Electronic supplementary material The online version of this article (doi:10.1007/s13361-012-0368-0) contains supplementary material, which is available to authorized users.

Correspondence to: Thomas R. Rizzo; e-mail: thomas.rizzo@epfl.ch peptide fragment ions, including theoretical calculations $[9,10]$, multi-stage mass spectrometry (MS/MS, or $\mathrm{MS}^{n}$ ) [3, 4, 11-28], ion mobility spectrometry (IMS) [29, 30], hydrogen-deuterium exchange (HDX) [22, 31, 32], and infrared multiple photon dissociation (IRMPD) spectroscopy $[5,22,31-42]$. While spectroscopy is a particularly powerful way to obtain detailed information about the structures of gas phase molecules, approaches based on IRMPD feature certain drawbacks. In addition to the complications implied by the multiple photon absorption process [43], the fact that all structural isomers are sampled at the same time, usually at room temperature, complicates the comparison to theoretical calculations and, hence, spectral assignments. With increasing complexity of the fragment ion structures, support from other sources of information becomes necessary for unraveling complicated IRMPD spectra. This can be achieved by combining spectroscopy with other techniques [22, 31, 32] or by comparison of the spectra with chemically modified species in which cyclization is either induced or inhibited [36, 38, 39, 42, 44]. 
Another approach to unraveling the spectra of different conformations is to use infrared-ultraviolet (IR-UV) doubleresonance spectroscopy in a low temperature ion trap [45]. Highly resolved electronic spectra of cold molecules [46, 47] allow labeling individual conformers via a UV transition followed by infrared depletion of the photofragment signal arising from the labeled conformer. Scanning an IR depletion laser generates selective vibrational spectra of only the labeled conformer [48-51]. By allowing selective and separate characterization of different fragment ion structures and conformations, such spectra provide the most stringent benchmarks to constrain theoretical calculations $[52,53]$.

Here we present the first application of IR-UV double resonance photofragment spectroscopy in a low-temperature radio-frequency (rf) ion trap for the structural investigation of peptide fragment ions. We investigate $b$ - and $a$-type fragments generated from leucine-enkephalin (YGGFL) as a first test case for our approach.

Leucine-enkephalin is a prototypical model pentapeptide, which is commonly used as a standard for mass-spectrometric instruments [54]. Its fragmentation products have been investigated by IRMPD spectroscopy [32, 34, 35], HDX [32] and IMS [29]. It is thus a suitable model system for test purposes and for comparing the results obtained by different approaches. In addition to oxazolone structures, cyclic isomers were reported for the $b_{3}$ and the $b_{4}$ ions in these experiments $[29,32,34,35]$, while $b_{2}$ ions seem to exhibit exclusively an oxazolone structure $[32,55]$. A linear but rearranged structure was identified as a major isomer for the $a_{4}$ ion $[6,56]$, but cyclic intermediates have been proposed to contribute as well [35].

The goal of this work is to use IR-UV double resonance photofragment spectroscopy in a cold ion trap to identify unambiguously the structural isomers and conformers of CID fragments of this benchmark molecule. We measure conformer-specific vibrational spectra of YGGFL $b_{2}, b_{3}, b_{4}$, and $a_{4}$ fragment ions in both the XH stretching region and in the fingerprint region $[5,31,32,34-40]$ on the same instrument. We find different conformers of oxazolone isomers with protonation on the N-terminus for all $b$-type ions, and two conformers of a rearranged $a_{4}$ structure. Conformational structures are analyzed in more detail with the support from density functional theory calculations.

\section{Experimental}

\section{Methods}

Our experimental approach [45] has been described in detail elsewhere [57]. In brief, we produce protonated YGGFL $\left([\mathrm{YGGFL}+\mathrm{H}]^{+}\right)$by nano-electrospray ionization from 50 or $100 \mu \mathrm{M}$ solutions in $1 / 1$ water/methanol mixtures, to which $0.1 \%$ of acetic acid is added. The $[\mathrm{YGGFL}+\mathrm{H}]^{+}$ions enter the tandem mass spectrometer through a stainless steel metal capillary, which directs them into an ion funnel. A hexapole ion guide then guides the compressed ion beam from the funnel exit to the first quadrupole mass filter. We set the acceleration voltages such that collisions with the background gas in the source region lead to fragmentation of the $[\text { YGGFL }+\mathrm{H}]^{+}$ions. We select a particular fragment ion (which we now call the parent) by its mass to charge ratio $\left(b_{2} m / z=222, b_{3} m / z=279, b_{4} m / z=426\right.$, or $\left.a_{4} m / z=398\right)$ to be transmitted through the first quadrupole mass filter. The mass-selected ions enter a static quadrupole deflector that turns them $90^{\circ}$ into an octopole ion guide, which can also be used for pre-trapping the ions before their injection into the cold, 22-pole ion trap [58-60]. After ejection from the octopole, the ions are turned $90^{\circ}$ once again and sent through a stack of deceleration lenses in front of the 22-pole trap.

Before the ions arrive at the cold trap a pulse of $\mathrm{He}$ gas is injected into the trap housing, which is maintained at a temperature around $4 \mathrm{~K}$ by a closed-cycle He cryostat. Upon the arrival of the ions in the trap, collisions with the cold $\mathrm{He}$ buffer gas atoms ensure their trapping and efficient cooling of translational and internal degrees of freedom. From the intensity of hot band transitions in the UV spectra, we estimate internal vibrational temperatures of the fragment ions to be in the range of $8-10 \mathrm{~K}$. The narrow line widths (around $2 \mathrm{~cm}^{-1}$ ) of the peaks are indicative of low rotational temperatures.

For laser-induced UV photofragmentation spectroscopy we send a 1-3 mJ UV laser pulse from the frequencydoubled output of a tunable dye laser down the axis of the 22-pole ion trap. This pulse promotes the parent ions to their first excited electronic state, which is at an energy above their dissociation threshold and, consequently, some fraction of them dissociate. After a $50 \mathrm{~ms}$ trapping period, we release the remaining parent ions and their laser-induced fragments from the 22-pole. Another quadrupole deflector turns them $90^{\circ}$, directing them through the analyzing quadrupole mass filter. On alternating cycles, we detect either the intact parent ion or a suitable laser-induced fragment ion (vide infra) on a channeltron detector. We generate an electronic spectrum of the parent ions by detecting the number of laser-induced fragment ions as a function of the UV wavenumber. By dividing this by the number of parent ions from the previous trapping cycle, we compensate for long-term fluctuations of the nano-electrospray source and in the CID process.

To acquire conformation-selective vibrational spectra, we fix the UV laser on one of the observed transitions in the electronic spectrum of a parent ion and pass an IR pulse from a tunable OPO $(4-10 \mathrm{~mJ}$ in the $\mathrm{XH}$ stretching range, 1$2 \mathrm{~mJ}$ in the fingerprint range by difference frequency mixing in a $\mathrm{AgGaSe}_{2}$ crystal) through the 22-pole trap 100-200 ns before the UV laser pulse. Vibrational excitation of the fragment ions leads to a depopulation of their ground state level, which we detect as a dip in the abundance of the UV laser-induced fragmentation product. Because we only detect the depletion of ions that contribute to the selected UV peak with this approach, we selectively investigate different isomers and conformers of the peptide fragment ions, as long as their UV spectra are resolved. 
In all experiments, we normalize the measured spectra linearly to the power of the scanned laser, which we measure with a pyroelectric detector.

Leucine-enkephalin with natural isotopic abundance was obtained from Bachem (Bubendorf, Switzerland). For supporting the assignment of individual vibrational bands, we record infrared spectra of selectively ${ }^{15} \mathrm{~N}$ labeled isotopologues of some fragment ions. For this purpose, we use YGGFL, where either the phenylalanine residue $\left(\mathrm{YGGF}^{*} \mathrm{~L}\right)$ or the second glycine and the phenylalanine residues $\left(\mathrm{YGG}^{*} \mathrm{~F}^{*} \mathrm{~L}\right)$ are labeled with ${ }^{15} \mathrm{~N}$ at the amide position. The labeled peptides were obtained from Anawa (Wangen, Switzerland) with $>97 \%$ isotopic purity.

\section{Theoretical Predictions}

A recently developed conformational search engine devised to deal with protonated peptides and their fragments was used to scan the potential energy surface (PES) of the $b_{3}$ ion of protonated YGGFL. These calculations began with molecular dynamics simulations using the Discover program (Biosym Technologies, San Diego, CA, USA) in conjunction with the AMBER force field [61] modified in-house in order to enable the study of structures with protonated or neutral imine and oxazolone groups. During the dynamics calculations simulated annealing techniques are used to produce candidate structures for further refinement, applying full geometry optimization using the AMBER force field. A conformer family search program developed in Heidelberg analyzed these optimized structures. This program groups optimized structures into families for which the most important characteristic torsion angles of the molecule are similar. The most stable species in the families were then fully optimized at the PM3, HF/3-21G, B3LYP/6$31 \mathrm{G}(\mathrm{d})$, and finally at the B3LYP/6-31+G(d,p) levels. The conformer families were regenerated at each level and only structurally nondegenerate conformers were recomputed at the next level to prevent wasting computer time (i.e., only one of $\mathrm{N}$ identical structures is recomputed at the next level). Structures of the YG $b_{2}$ ion were taken from Reference [55]. Structures for the $b_{4}$ and $a_{4}$ ions were taken from previous PES scans $[34,35,56]$, which were refined in the present work by including additional species at the higher theoretical levels. Theoretical vibrational spectra were calculated in the harmonic approximation on B3LYP/6-31+G(d,p) level using Gaussian 03 [62] or Gaussian 09 [63]. For better comparison to the experimental spectra, the theoretically predicted wavenumbers are scaled by factors of 0.954 and 0.98 in the XH stretching and fingerprint regions of the vibrational spectrum, respectively. Values mentioned in the text refer to the scaled wavenumbers for facilitating comparison to the experimental values. Relative energy differences of conformer structures indicated in the Figures include zero-point energy corrections in the harmonic approximation.

\section{Results and Discussion}

In this section we present UV photofragment spectra and conformer-selective IR-UV double resonance spectra of different CID fragment ions $\left(b_{2} m / z=221, b_{3} m / z=278\right.$, $b_{4} \mathrm{~m} / z=425$, or $a_{4} \mathrm{~m} / \mathrm{z}=397$ ) derived from protonated leucine-enkephalin $\left([\mathrm{YGGFL}+\mathrm{H}]^{+}\right)$. We first give an overview of the UV spectra, followed by a discussion of the conformation-selective IR spectra of the fragment ions and their comparison to theoretical predictions.

\section{UV Photofragmentation Spectra}

The two aromatic rings of the tyrosine (Y) and phenylalanine (F) side chains of YGGFL are suitable chromophores for UV photofragment spectroscopy. Whereas in the smaller $b_{2}$ and $b_{3}$ fragment ions only the $\mathrm{Y}$ residue remains after dissociation, the larger $a_{4}$ and $b_{4}$ fragments retain both $\mathrm{Y}$ and $\mathrm{F}$.

The UV spectra of protonated tyrosine and phenylalanine are well separated [48], with the former lower in energy by more than $2000 \mathrm{~cm}^{-1}$. Electronic excitation leads to a cleavage of the $\mathrm{C}_{\alpha}-\mathrm{C}_{\beta}$ bond in the aromatic amino acid residues $[48,64]$ (i.e., the loss of either a benzyl $(m / z=[\mathrm{M}+\mathrm{H}-91])$ or a $p$ hydroxy benzyl radical $(m / z=[\mathrm{M}+\mathrm{H}-107]))$. These fragmentation channels are not abundant in CID and are thus well suited for photofragment spectroscopy. In the $b_{4}$ and $a_{4}$ ions, both fragmentation channels lead to the same UV spectra. The photofragmentation spectra in the region of the $\mathrm{Y}$ chromophore for the different fragment ions are shown in Figure 1. Photofragmentation spectra of $a_{4}$ and $b_{4}$ in the region of the $\mathrm{F}$ chromophore are shown in Figure $\mathrm{S} 1$ of the Supplementary Material. The arrows on selected peaks in Figure 1 mark the electronic band origins. Different conformers can be identified from the selective IR-UV depletion experiments (vide infra) for $b_{2}, b_{4}$, and $a_{4}$, whereas only one conformer is observed for $b_{3}$.

The electronic band origins of the $b_{2}$ ion conformers appear at similar positions (A: $35081 \mathrm{~cm}^{-1}$, B: $35117 \mathrm{~cm}^{-1}$ ) to those of bare protonated tyrosine $\left(35081 \mathrm{~cm}^{-1}\right.$ and $35111 \mathrm{~cm}^{-1}$ ) [48], while the larger $b$-ions and the $a_{4}$ ion show blue-shifts that increase with the size of the fragment ion $\left(b_{3}: 35172 \mathrm{~cm}^{-1} ; a_{4}: \mathrm{A}: 35179 \mathrm{~cm}^{-1}\right.$, B: $35238 \mathrm{~cm}^{-1} ; b_{4}$ : A: $35409 \mathrm{~cm}^{-1}$, B: $\left.35415 \mathrm{~cm}^{-1}\right)$.

In all of the spectra shown in Figure 1, low-frequency vibrational progressions extend from the band origin towards higher wavenumber. For those ions with multiple conformations, the partial overlap of the UV spectra results in a dense collection of lines. A clearer distinction of the contributing conformations is achieved in the region of the $\mathrm{F}$ chromophore for $a_{4}$ and $b_{4}$ (see Figure S1 in the Supplementary Material), where two and four conformations can be identified, respectively. The overlap of the dense vibrational progressions in the region of the $\mathrm{Y}$ chromophore can hamper a clear identification of the band origins, and only those that could be identified unambiguously are marked in Figure 1. 


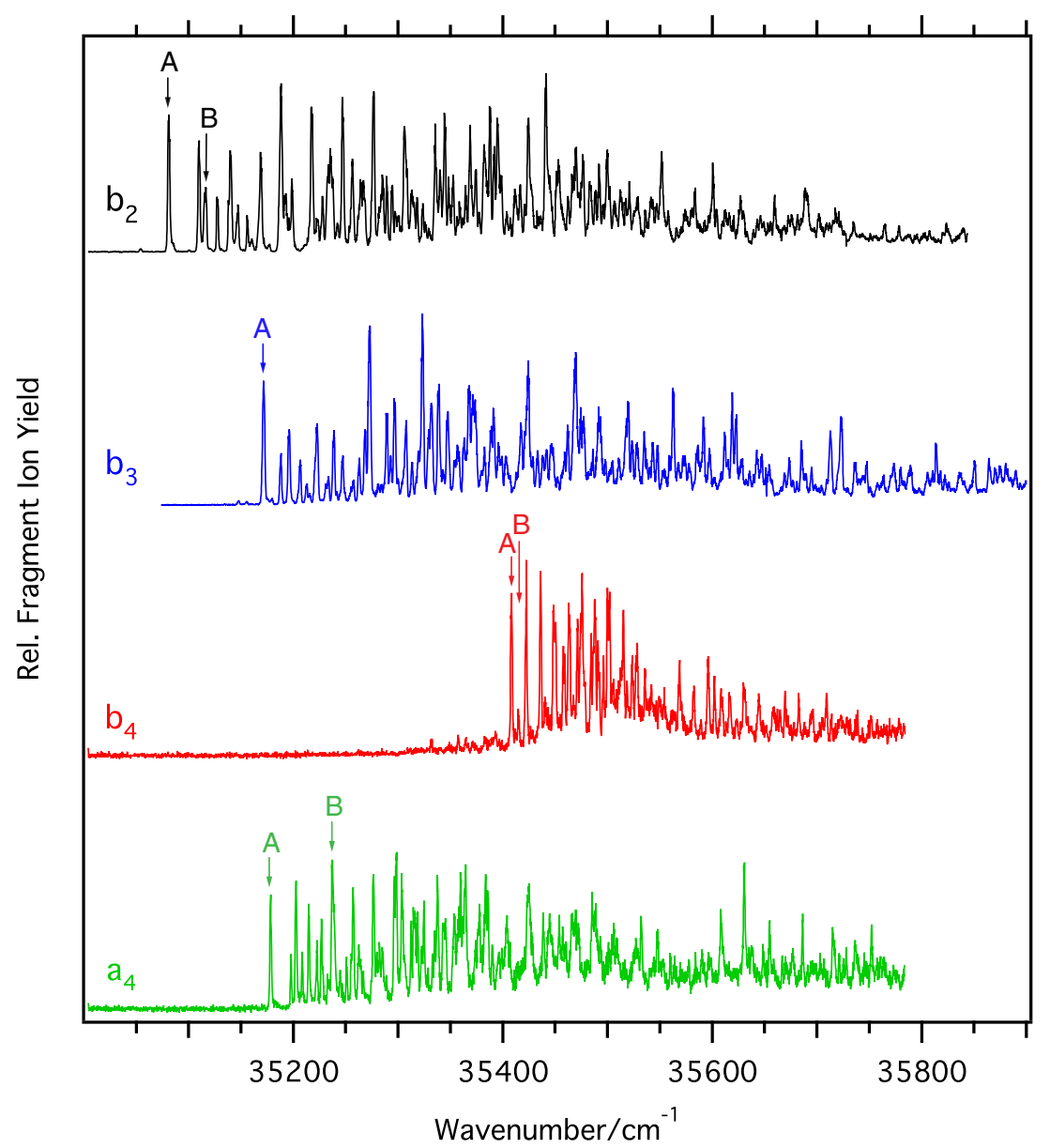

Figure 1. UV photofragment spectra of different $b$-type ions $\left(b_{2}\right.$, black trace, $b_{3}$, blue trace, and $b_{4}$, red trace) and of the $a_{4}$-ion (green trace) from CID of YGGFL in the region of tyrosine (Y) electronic excitation. The letters $A$ and $B$ indicate the band origins of different conformers

We observe small hot band transitions from vibrationally excited states of low frequency vibrations at lower wavenumber from the band origins. Their intensities provide a measure of the internal vibrational temperatures of the fragment ions, which we determine to be in the range of 8-10 K, assuming a Boltzmann distribution. Narrow line widths of the vibronic transitions (typically around $2 \mathrm{~cm}^{-1}$ ) indicate low rotational temperatures. The low temperatures and narrow vibronic lines are a prerequisite for IR-UV depletion experiments, which we describe in the following section.

\section{Conformer-Selective Vibrational IR Spectra}

On the basis of the UV photofragment spectra in Figure 1, we perform IR-UV double-resonance spectroscopy of the CID fragment ions. In the following sections we describe the conformer-selective vibrational spectra obtained for the $b$ type ions $\left(b_{2}, b_{3}\right.$, and $\left.b_{4}\right)$ and the $a_{4}$ ion from YGGFL. The experimentally observed vibrational band positions are summarized in Tables S1 to S4 in the Supplementary Material. To facilitate comparison between the different fragment ions, we first discuss the $b$-type ions of increasing size and then the $a_{4}$ ion. The structure of the respective sections is similar throughout the manuscript.

The $b_{2}$ Ion We identify two distinguishable isomers for the $b_{2}$ ion from the UV spectra with the origin transitions at $35081 \mathrm{~cm}^{-1}$ (marked $\mathrm{A}$ in Figure 1) and at $35117 \mathrm{~cm}^{-1}$ (B). Franck-Condon progressions in vibrational modes of $29 \mathrm{~cm}^{-1}$ (A) and $30 \mathrm{~cm}^{-1}$ (B) build off of these UV peaks.

The two main chemical structures that have been proposed for $b_{2}$ ions are oxazolone isomers [11] with a five-membered ring at the $\mathrm{C}$-terminal side of the molecule, or six-membered diketopiperazine rings [65, 66]. Although diketopiperazines are assumed to be the thermodynamically more stable isomers, oxazolones were found to prevail in many investigations $[11,15,31,32,36,38,41,42,67]$. The presence of histidine can apparently lower the high barrier to formation [66] of the two cis-amide bonds in diketopiperazines [39]. We show conformer selective IR spectra obtained at low temperatures for the two isomers in Figure 2, 

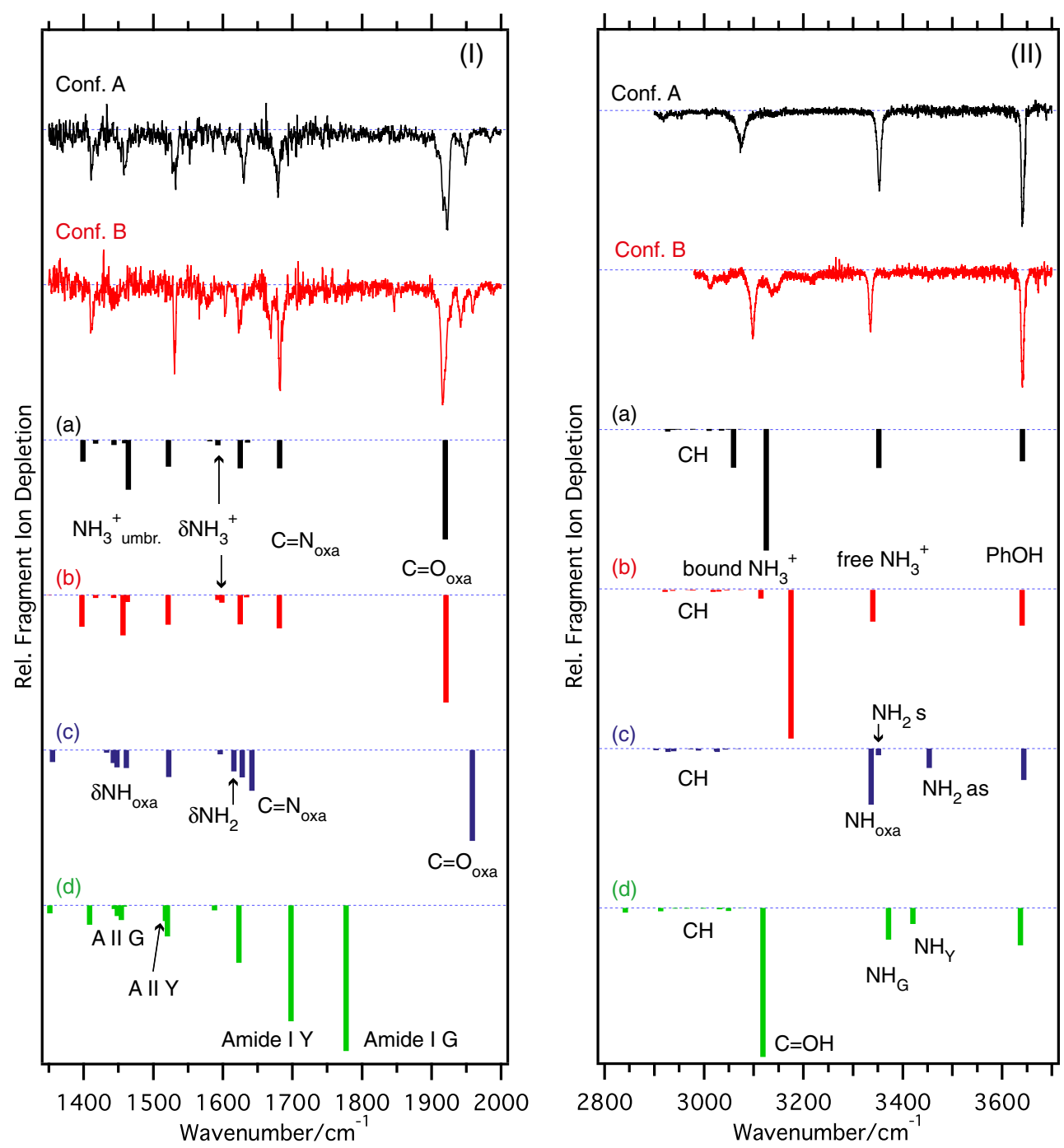

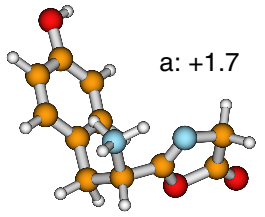

Oxazolone $\mathrm{N}$-ter

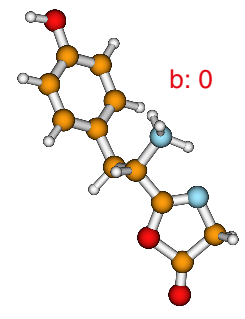

Oxazolone N-ter

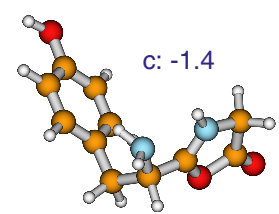

Oxazolone oxa

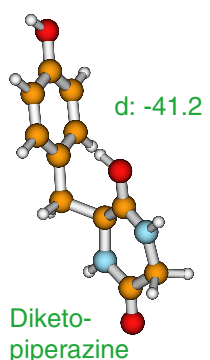

Figure 2. Vibrational spectra of two conformers of the $Y G b_{2}$ ion obtained by IR-UV double resonance (monitoring the [M $\left.+\mathrm{H}-107\right]^{+}$ fragment ion) and their comparison with calculated spectra (B3LYP/6-31+G(d,p)) for the lowest energy species: (a), (b): oxazolone with protonation on the N-terminus; (c) oxazolone with protonation on the oxazolone ring; (d) diketopiperazine. Assignment labels for the theoretical spectra are inserted for vibrations referred to in the text. The conformational structures from the calculations and relative energies $/ \mathrm{kJ} \mathrm{mol}^{-1}$ (including harmonic zero point energy correction) are shown below the figure. The intensity of the diketopiperazine $\mathrm{C}=\mathrm{OH}$ stretching vibration in the calculated spectra (green trace) is truncated for better visibility of the lower intensity vibrations

along with calculated spectra both for the lowest energy oxazolone and diketopiperazine structures.

Both isomers show similar spectra, indicating that they are conformational isomers of the same chemical structure. The spectra in Figure 2 immediately suggest oxazolone structures for the $b_{2}$ ion of YGGFL. As the carbonyl groups have been identified as the most stable protonation sites for diketopiperazines without basic amino acid residues $[15,38$, $41,55]$, one should expect two amide NH stretch bands and the $\mathrm{C}=\mathrm{O}-\mathrm{H}^{+}$stretching vibration in the light atom stretching 
region of the vibrational spectrum for diketopiperazines. Instead, we observe one band that we attribute to a free ammonium $\mathrm{NH}$ (at $3353 \mathrm{~cm}^{-1}$ and $3335 \mathrm{~cm}^{-1}$ for $\mathrm{A}$ and $\mathrm{B}$, respectively, see also Table $\mathrm{S} 1$ in the Supplementary Material) and peaks in the region of bound ammonium $\mathrm{NH}$ vibrations: for $\mathrm{A}$ an intense peak at $3073 \mathrm{~cm}^{-1}$ with some shoulder to lower wavenumber, and for B an intense peak at $3097 \mathrm{~cm}^{-1}$ and some peaks with lower intensity at $3135 \mathrm{~cm}^{-1}$ and $3010 \mathrm{~cm}^{-1}$. Anharmonic couplings and partial overlap with the highest wavenumber $\mathrm{CH}$ stretching vibration can lead to complicated band patterns in this region, but we can clearly identify the presence of bound ammonium NHs from the spectra. A similar pattern has been observed in the spectra of the protonated amino acids phenylalanine and tyrosine [48]. It was explained by the hydrogen-bonding pattern of the protonated ammonium group, which can establish one hydrogen bond to the aromatic ring and one to the carbonyl group [48]. The third ammonium NH is not engaged in a hydrogen bond and gives rise to a peak at higher wavenumber. A similar pattern for the $\mathrm{NH}$ vibrations of the YG $b_{2}$ ion suggests N-terminally protonated oxazolone structures with a similar hydrogen-bonding pattern. The $\mathrm{OH}$ stretching vibration of the tyrosine side chain appears slightly red-shifted in YG $b_{2}$ at $3641 \mathrm{~cm}^{-1}$ with respect to protonated tyrosine. It is however not a sensitive probe for the structure of these species.

Room temperature IRMPD spectra in the XH stretching region were recently used to diagnose the protonation site in $b_{2}$ oxazolones [41, 42], and structures with protonation at the oxazolone ring nitrogen have been reported as the major species observed in these investigations for the YI and GG $b_{2}$ ions, respectively. In contrast, under our conditions, we can largely exclude these in favor of species protonated on the N-terminal nitrogen atom for the YG $b_{2}$ ion.

More detailed information about the conformational structures of A and B can be obtained through comparison with suitable theoretical predictions. Good agreement is obtained for two oxazolone isomers [55] with protonation on the N-terminus. The positions of the bound $\mathrm{NH}$ vibrations are difficult to predict accurately when using a harmonic approximation, even upon application of scaling factors. It was shown that a perturbative approach for anharmonic predictions can partially remedy this [48]. We conclude that low energy oxazolone isomers with $\mathrm{N}$-terminal protonation are in good agreement with our experimental observations.

Figure 2 also shows calculated spectra for the lowest energy oxazolone isomer with protonation on the oxazolone ring (conformer c, blue trace). Despite its lower zero pointcorrected energy, we can exclude the presence of such structures because we do not observe asymmetric and symmetric $\mathrm{NH}_{2}$ stretching vibrations in our spectra, which we would expect if the $\mathrm{N}$-terminus were not protonated.

The diketopiperazine isomer can also be ruled out, even though it is the global minimum structure in the DFT calculations (conformer d, green trace). From the predictions we would expect two amide vibrations and the $\mathrm{C}=\mathrm{OH}$ vibration, which we do not see in the experimental spectra. Isomerization of the N-terminal cis-amide bonds, which is required for formation of the diketopiperazine, is apparently prevented by high barriers $[2,66,68]$.

The bound ammonium NH stretch vibrations in our measured spectra provide a clear fingerprint for N-terminally protonated oxazolone structures. Figure 2 illustrates that none of the other isomers is expected to show intense vibrations in the same range. Another fingerprint for oxazolone isomers can be obtained from measurements at lower wavenumbers. It was shown in IRMPD experiments that oxazolones possess a characteristic carbonyl stretching vibration that occurs at comparatively high wavenumbers (around 1750-1950 $\mathrm{cm}^{-1}$ ) [31, 32, 36, 38, 39, 55]. We therefore measured vibrational spectra in the region between $1350 \mathrm{~cm}^{-1}$ and $2000 \mathrm{~cm}^{-1}$, which we show on the left side of Figure 2 (see also Table S1 in the Supplementary Material).

We find the typical oxazolone $\mathrm{C}=\mathrm{O}$ stretch vibration at about $1923 \mathrm{~cm}^{-1}$ (A) and $1916 \mathrm{~cm}^{-1}$ (B). Small peaks at higher wavenumber are probably due to anharmonic couplings (e.g., Fermi resonances). Apart from that, the $\mathrm{C}=\mathrm{N}$ stretching vibration of the oxazolone ring (A: $1680 \mathrm{~cm}^{-1}$, B: $1683 \mathrm{~cm}^{-1}$ ) and bending vibrations of the protonated ammonium group (e.g., at $1603 \mathrm{~cm}^{-1}, 1458 \mathrm{~cm}^{-1} \mathrm{~A}$, or at $1603 \mathrm{~cm}^{-1}$, $1444 \mathrm{~cm}^{-1}$ B) are the most characteristic fingerprints in this region. These observations give further support for Nterminally protonated oxazolone structures. For an oxazolone-protonated isomer, the oxazolone $\mathrm{C}=\mathrm{O}$ stretching vibration would be expected at even higher wavenumber, while the $\mathrm{C}=\mathrm{N}$ stretching vibration should appear at lower wavenumber. Instead of $\mathrm{NH}_{3}{ }^{+}$bending bands, the bending vibrations of the protonated oxazolone ring nitrogen and of the nonprotonated $\mathrm{NH}_{2}$ group should be observed. Diketopiperazines would give rise to two amide I vibrations that both would occur below $1800 \mathrm{~cm}^{-1}$. At lower wavenumbers they would also show the corresponding amide II vibrations.

Protonation at the oxazolone ring or diketopiperazine formation can thus be largely ruled out from these investigations. Comparison between the experiments and theoretical predictions gives strong support for N-terminally protonated oxazolone structures from both investigated frequency regions. The most characteristic fingerprints for this assignment are the observation of $\mathrm{NH}$ stretching vibrations that are assigned to the protonated ammonium group of the $\mathrm{N}$-terminus in the $\mathrm{XH}$ stretching region and $\mathrm{C}=\mathrm{O}$ stretching vibrations from the oxazolone carbonyl group in the fingerprint region. The observed band pattern in the NH stretch region suggests that the $\mathrm{NH}_{3}{ }^{+}$group establishes two hydrogen bonds (one to the $\pi$ system of the aromatic ring of the tyrosine side chain and the other to the oxazolone ring nitrogen atom), whereas the third $\mathrm{NH}$ is rather free. Two conformations with relatively low energy from the DFT calculations are found to give a good explanation for the experimental observations. 
The $b_{3}$ Ion As is indicated in Figure 1, we observe one single conformation for the $b_{3}$ ion with a band origin in the UV at $35172 \mathrm{~cm}^{-1}$ Two low-frequency vibrational progressions are built off the band origin with spacings of $17 \mathrm{~cm}^{-1}$ and $25 \mathrm{~cm}^{-1}$.

Figure 3 displays the IR-UV double resonance spectrum obtained for $b_{3}$ in the $\mathrm{XH}$ stretch region and compares it to the spectra of the two $b_{2}$ conformations. The similarity between the spectra suggests an analogous assignment (see also Table S2 in the Supplementary Material).

With respect to $b_{2}$, the $b_{3}$ ion is extended by one glycine residue, which gives rise to one additional amide band. We find it partially overlapping with the free $\mathrm{NH}$ band of the ammonium group and thus observe a doublet with peak positions at $3351 \mathrm{~cm}^{-1}$ and $3347 \mathrm{~cm}^{-1}$. The signals from the bound ammonium $\mathrm{NH}$ stretches appear with similar intensities at approximately $3180 \mathrm{~cm}^{-1}$ and $3113 \mathrm{~cm}^{-1}$. From this we assign an oxazolone structure with protonation at the $\mathrm{N}$ -

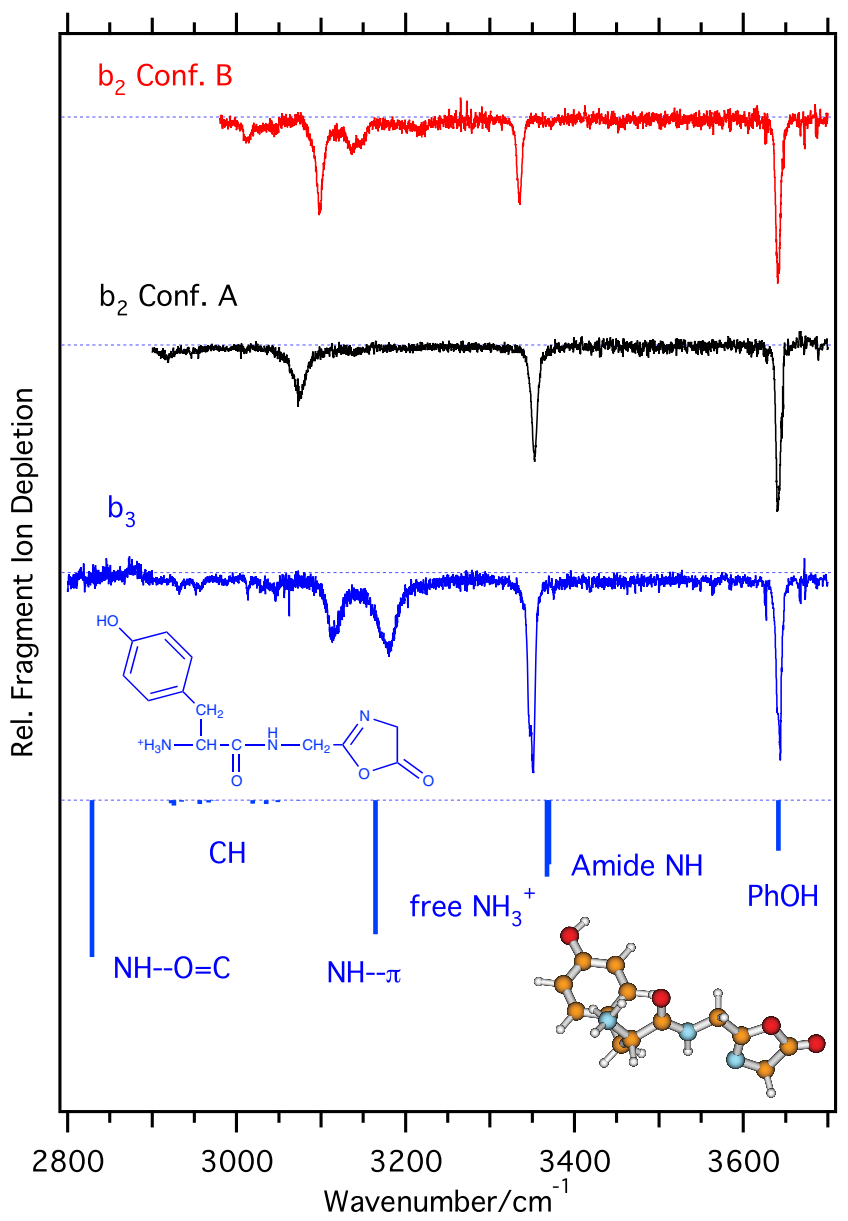

Figure 3. Comparison of IR-UV double resonance depletion spectra of $b_{3}$ (blue trace) with spectra of conformations A (black trace) and $\mathrm{B}$ (red trace) of $b_{2}$ (all monitoring the $[\mathrm{M}+\mathrm{H}-107]^{+}$ fragment ion) and with theoretical predictions from DFT calculations (B3LYP/6-31+G(d,p)). Note that the shown structure had the lowest DFT energy, also in comparison with oxazolone-protonated isomers terminus. The ammonium group displays a similar hydrogen-bonding pattern to the case of $b_{2}$, with two of the three $\mathrm{NHs}$ forming strong hydrogen bonds, while the third one is rather free and appears at higher wavenumber. The intramolecular hydrogen bond strength in $b_{3}$ seems to be somewhat weaker than in $b_{2}$ based on the red shifts of the bound ammonium NH vibrations with respect to the free ammonium NH. The position of the amide NH vibration is indicative of a weak intramolecular hydrogen bond as well.

Further support for the oxazolone structure with protonation on the N-terminal nitrogen comes from isotopic substitution. We labeled the second glycine and the phenylalanine in YGGFL with ${ }^{15} \mathrm{~N}\left(\mathrm{YGG}^{*} \mathrm{~F}^{*} \mathrm{~L}\right)$, such that in the $b_{3}$ ion with the sequence YGG the nitrogen from the second glycine is substituted with ${ }^{15} \mathrm{~N}$ (YGG*). This substitution produces no shift whatsoever in the region of the $\mathrm{XH}$ stretches, in agreement with an N-terminally protonated oxazolone structure in which this nitrogen atom in the oxazolone ring is not protonated. On the other hand there is one band in the fingerprint region at $1683 \mathrm{~cm}^{-1}$ that shifts by $13 \mathrm{~cm}^{-1}$ to the red upon this isotopic substitution (see Figure 4). We assign this band to the $\mathrm{C}=\mathrm{N}$ stretching vibration of the oxazolone ring. The observed isotopic shift is lower than expected from theoretical predictions (approximately

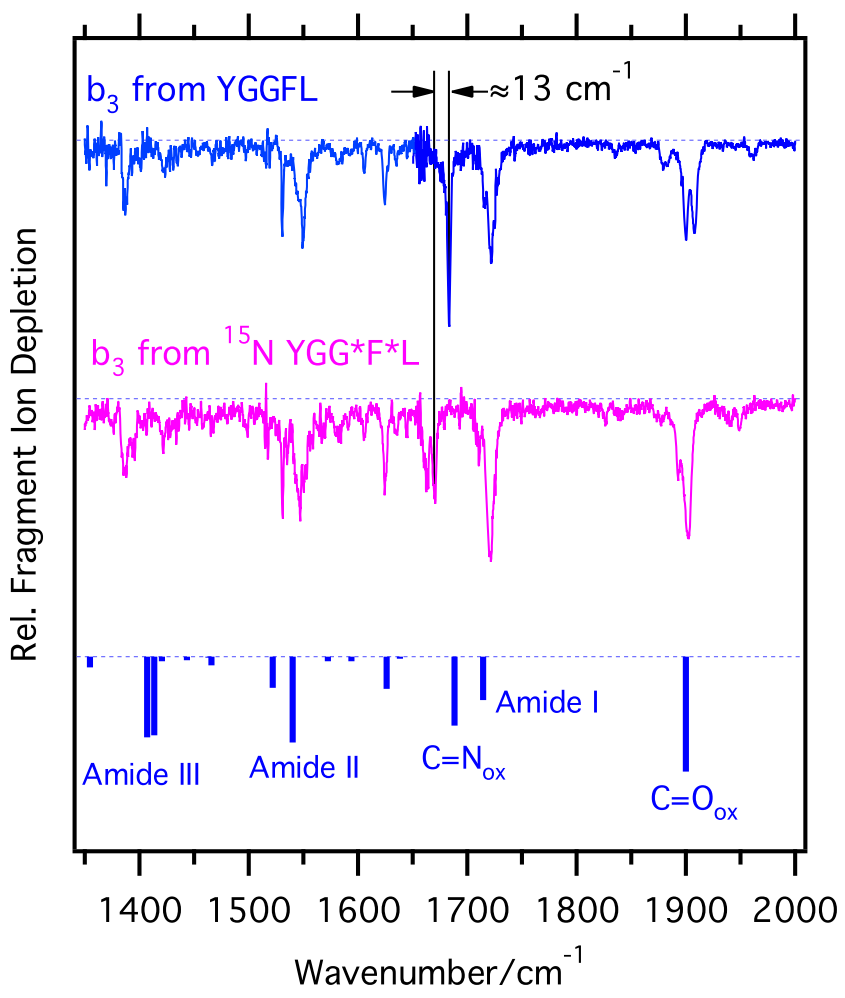

Figure 4. IR-UV double-resonance spectrum of $b_{3}$ ions (monitoring the $[\mathrm{M}+\mathrm{H}-107]^{+}$fragment ion) from YGGFL (blue trace) and ${ }^{15} \mathrm{~N} Y \mathrm{YG}^{\star} \mathrm{F}^{\star} \mathrm{L}$ (pink trace) and theoretical predictions from DFT calculations (B3LYP/6-31+G(d,p)). Labels for some characteristic vibrations are inserted next to the theoretical predictions 
$\left.19 \mathrm{~cm}^{-1}\right)$. At the same time, we observe a new band that arises at $1663 \mathrm{~cm}^{-1}$. We conclude that a Fermi resonance pattern is tuned into resonance through the isotopic shift. Mathematical deperturbation of the resonance pattern increases the experimental isotopic shift to approximately $16 \mathrm{~cm}^{-1}$, in better agreement with the predictions.

The fact that we do not observe any isotopic shift of $\mathrm{NH}$ stretching or bending vibrations provides further support that the oxazolone is protonated on the N-terminus and that the ring nitrogen does not have a proton. The agreement of theoretical predictions for the lowest energy N-terminally protonated oxazolone isomer is good in the fingerprint region (Figure 4) and for most of the vibrations in the $\mathrm{XH}$ stretching region (Figure 3). However, the NH stretching vibration of the ammonium $\mathrm{NH}$ that is hydrogen-bonded to the carbonyl group of the first glycine residue is not well predicted in the calculations and appears more than $280 \mathrm{~cm}^{-1}$ red-shifted with respect to the lower wavenumber ammonium band in the experiment.

To further investigate this, we calculated the vibrational wavenumbers of the ammonium $\mathrm{NH}$ vibrations as a function of the relative orientation between the carbonyl group and the $\mathrm{NH}$ that is hydrogen bonded to it by setting the dihedral angle defined by the carbonyl oxygen, the carbon atom to which the $\mathrm{NH}_{3}^{+}$is bound, the nitrogen atom, and the hydrogen atom to defined values, while all other coordinates were allowed to relax freely. An increase of the value of this angle results in a weakening of the $\mathrm{NH}-\mathrm{OC}$ hydrogen bond and in a more favorable orientation for the $\mathrm{NH}-\pi$ hydrogen bond. At the same time, the red shift of the $\mathrm{NH}-\mathrm{OC}$ stretching vibration is decreased. The $\mathrm{NH}$ stretch vibrations of the free $\mathrm{NH}$ and the $\mathrm{NH}$ group that is hydrogen bonded to the aromatic $\pi$ system show only minor changes (see Figure S2 in the Supplementary Material). We conclude that an overestimation of the strength of the $\mathrm{NH}-\mathrm{OC}$ hydrogen bond leads to a considerable overestimation of the vibrational red shift of this group. In the DFT calculations that we apply here, which do not take dispersion interactions into account, an underestimation of the $\mathrm{NH}-\pi$ interaction strength might reinforce this effect. The good match of the other vibrations with the experimental spectrum indicates that the conformational structure in our experiments is similar to the calculated one shown in Figure 3, but that the hydrogen bond between the $\mathrm{NH}$ and the $\mathrm{CO}$ group is overestimated by the calculations. Inclusion of corrections for the dispersion energy (e.g., dispersion-corrected DFT-D functional or ab initio MP2 calculations) should help to remedy these deficiencies. However, such calculations can be much more time-consuming for fragment ions of increasing size and were not in the scope of the present study.

The $b_{4}$ Ion The $b_{4}$ ion of YGGFL has been extensively studied previously using IMS [29], HDX [32], and IRMPD spectroscopy $[32,34,35]$. A mixture of oxazolone structures with protonation both on the oxazolone ring as well as on the N-terminus and of macrocyclic structures has been reported (see Scheme 1) [32, 34, 35]. In the case of mixtures of multiple isomers, selective investigation of the contributing isomers by our IR-UV double resonance depletion approach can be particularly useful in helping to deconvolute overlapping spectra.

Figure 5 displays the vibrational spectra of four different isomers of the $b_{4}$ ion from YGGFL that we can distinguish with our double-resonance technique together with those of ${ }^{15} \mathrm{~N}$-substituted isotopologues derived from YGGF*L and $\mathrm{YGG}^{*} \mathrm{~F}^{*} \mathrm{~L}$ (i.e., with ${ }^{15} \mathrm{~N}$ substitution on the phenylalanine or on the phenylalanine and the second glycine residue, respectively). We measured the depletion spectra using UV bands in the region of the phenylalanine chromophore because the dense and congested electronic spectrum in the tyrosine region did not allow unambiguous distinction of all<smiles>[NH3+][Ga]O[R4](=O)O[Na]</smiles><smiles>NC(Cc1ccc(O)cc1)C(=O)NCC(=O)NCC1=[NH+]C(Cc2ccccc2)C(=O)O1</smiles><smiles>O=C1CNC(=O)C(Cc2ccc(O)cc2)NC(=O)C(Cc2ccccc2)NC(=O)CN1</smiles>

\section{Macrocycle}

Scheme 1. Structural isomers for YGGFL $b_{4}$ according to References [32, 34, 35]: Oxazolone structures with protonation at the $\mathrm{N}$-terminus or on the oxazolone ring and macrocyclic structure 


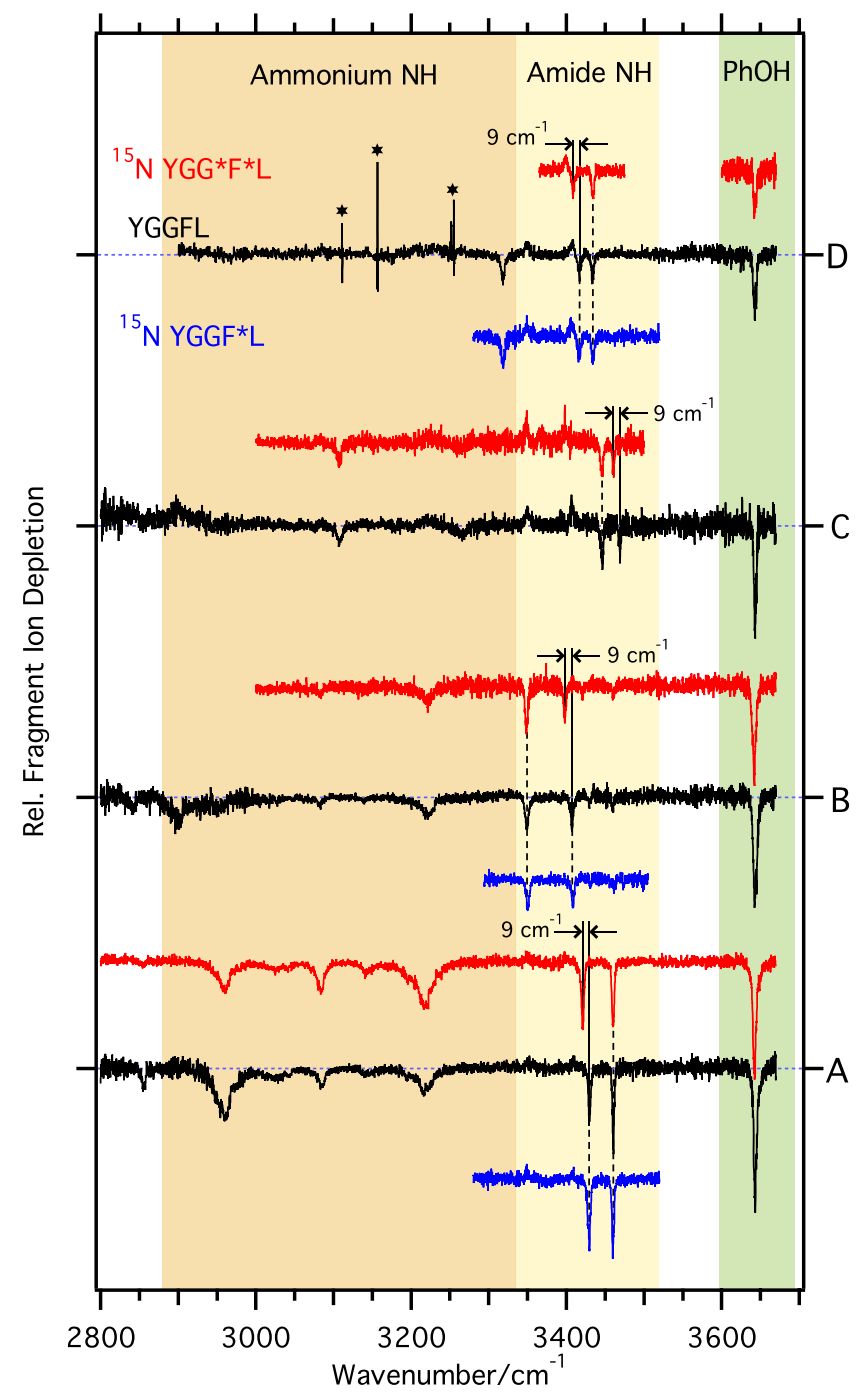

Figure 5. Conformer-selective IR-UV double resonance depletion spectra (monitoring the $[\mathrm{M}+\mathrm{H}-91]^{+}$fragment ion) of different isotopologues of the four $b_{4}$ conformational isomers $A, B, C$, and $D$. Black traces show the normal species, while blue traces correspond to $b_{4}$ ions derived from ${ }^{15} \mathrm{~N}$ YGGF*L, and red traces to $b_{4}$ ions formed from ${ }^{15} \mathrm{~N}$ $Y G G^{\star} F^{\star} L$. Isotopic shifts are marked in the spectra. Spikes from background signal instabilities in the spectrum of $D$ are marked with asterisks

four isomers in this range. Isomers $\mathrm{A}$ and $\mathrm{B}$ have their electronic band origins at $35409 \mathrm{~cm}^{-1}$ and $35415 \mathrm{~cm}^{-1}$, respectively, with low frequency vibrational progressions of $14 \mathrm{~cm}^{-1}$ in the tyrosine region. The UV spectra in the phenylalanine region are shown with assignments of the isomers A, B, C, and D in Figure S1 of the Supplementary Material.

An overview of the chemical structures of oxazolones with protonation on the $\mathrm{N}$-terminus or on the oxazolone ring nitrogen atom and of the macrocyclic structure that were assigned in previous investigations is shown in Scheme 1. In the region of $\mathrm{XH}$ stretching vibrations we expect two amide vibrations for the oxazolone species. For oxazolone isomers with protonation on the oxazolone ring, we also expect to observe the symmetric and antisymmetric $\mathrm{NH}_{2}$ stretching vibration of the neutral $\mathrm{N}$-terminal amine group, while the $\mathrm{NH}$ vibration of the protonated ring nitrogen should appear at lower wavenumber, in the region of ammonium vibrations. Oxazolone isomers with protonation on the Nterminus should display ammonium vibrations. For macrocyclic isomers, depending on the protonation site, we expect up to four amide vibrations as well as a signature from the proton stretch band (e.g., a $\mathrm{C}=\mathrm{O}-\mathrm{H}^{+}$stretching vibration).

All four isomers, A, B, C, and D in Figure 5, show two amide vibrations together with typical ammonium signatures (for a summary of the measured vibrational bands see Table S3 in the Supplementary Material), which would directly suggest $\mathrm{N}$-terminally protonated oxazolone isomers. For further support we investigated isotopologues of the $b_{4}$ ions that were produced from leucine-enkephalin with ${ }^{15} \mathrm{~N}$ substitution on the phenylalanine residue only or on the phenyalanine and the second glycine residue $\left({ }^{15} \mathrm{~N} \mathrm{YGGF}^{*} \mathrm{~L}\right.$ and $\mathrm{YGG}^{*} \mathrm{~F}^{*} \mathrm{~L}$ ). For substitution on the phenylalanine only we observe no spectral shift in the region of the $\mathrm{XH}$ stretching vibrations. For all isomers $\mathrm{A}, \mathrm{B}, \mathrm{C}$, and $\mathrm{D}$, one amide band displays an isotopic shift $\left(\sim 9 \mathrm{~cm}^{-1}\right)$ to lower wavenumber when the second glycine residue is additionally labeled. We can thus assign this band to the amide $\mathrm{NH}$ vibration of the second glycine residue (A: $3430 \mathrm{~cm}^{-1}$, B: $3407 \mathrm{~cm}^{-1}, \mathrm{C}: 3469 \mathrm{~cm}^{-1}$, D: $3417 \mathrm{~cm}^{-1}$ ). The other amide band (A: $3461 \mathrm{~cm}^{-1}$, B: $3348 \mathrm{~cm}^{-1}$, C: $3446 \mathrm{~cm}^{-1}$, D: $3434 \mathrm{~cm}^{-1}$ ) and the ammonium vibrations at lower wavenumbers do not display any isotopic shift. We thus assign the amide band to the first glycine residue and the ammonium vibrations to the protonated $\mathrm{N}$-terminal tyrosine residue.

Taken together, our data implies that the isomers A, B, C, and $\mathrm{D}$ are conformational isomers of the same chemical structure. We conclude that they all have an oxazolone structure in which the original sequence is conserved and in which the ionizing proton is located on the $\mathrm{N}$-terminus. This is also supported by IR-UV depletion spectra in the fingerprint region of the vibrational spectrum for conformers A and B, which we show in the Supplementary Material (Figure S3 and Table S3), and which display oxazolone carbonyl vibrations at approximately $1791 \mathrm{~cm}^{-1}$ (A) and $1787 \mathrm{~cm}^{-1}$ (B). Apart from the characteristic oxazolone $\mathrm{C}=\mathrm{O}$ stretching vibrations, we observe the most intense peaks for A at $1751 \mathrm{~cm}^{-1}, 1703 \mathrm{~cm}^{-1}$ (amide I), $1536 \mathrm{~cm}^{-1}$ (amide II), and $1449 \mathrm{~cm}^{-1}$ and for B at $1746 \mathrm{~cm}^{-1}, 1703 \mathrm{~cm}^{-1}$ (amide I), $1530 \mathrm{~cm}^{-1}$ (amide II), and $1442 \mathrm{~cm}^{-1}$ in this region. We could not obtain depletion spectra in this region for conformers $\mathrm{C}$ and $\mathrm{D}$ because of their lower UV peak intensities.

Our spectra provide information about conformer structures, which can be used as constraints for conformational searches in theoretical calculations [53]. The positions of the amide NH stretching bands are most informative for this. In conformers $\mathrm{A}$ and $\mathrm{D}$, the amide $\mathrm{NH}$ band of the second 
glycine residue appears at lower wavenumber than the first, while we observe the opposite in B and C. For C and D, the wavenumber differences between the amide bands are relatively small $\left(23 \mathrm{~cm}^{-1}\right.$ and $17 \mathrm{~cm}^{-1}$, respectively), while they are more widely separated in A and B $\left(31 \mathrm{~cm}^{-1}\right.$ and $59 \mathrm{~cm}^{-1}$ ). Together with the positions of the ammonium vibrations, these spectral features can provide information about the hydrogen-bonding patterns in the $b_{4}$ conformations. As shown in Figure S3, the oxazolone carbonyl vibrations of conformations A and B appear at relatively low wavenumber, which suggests that they are involved in some intramolecular interactions as well.

The increased size of the $b_{4}$ ion compared with $b_{2}$ and $b_{3}$ leads to higher conformational flexibility, and as a result only $\mathrm{D}$ shows a signal that can be attributed to a free ammonium $\mathrm{NH}$ stretch $\left(3319 \mathrm{~cm}^{-1}\right)$ similar to that observed in $b_{2}$ and $b_{3}$, while we observe only bound ammonium $\mathrm{NH}$ vibrations in $\mathrm{A}, \mathrm{B}$, and $\mathrm{C}$ (A: $3218 \mathrm{~cm}^{-1}$, $3084 \mathrm{~cm}^{-1}, 2961 \mathrm{~cm}^{-1}$; B: $3222 \mathrm{~cm}^{-1}, 3082 \mathrm{~cm}^{-1}$, $2900 \mathrm{~cm}^{-1}$; C: $3265 \mathrm{~cm}^{-1}, 3106 \mathrm{~cm}^{-1}$ ).

Despite extensive theoretical sampling of the conformational space for $\mathrm{N}$-terminally protonated $b_{4}$ oxazolone isomers, we could not identify suitable candidates that reproduce all the details in the experimental observations. We show selected examples, which can reproduce parts of the experimental spectra, for conformers A, C, and D in Figure 6 before discussing the remaining deficiencies. The selected structures predict the amide $\mathrm{NH}$ vibration of the

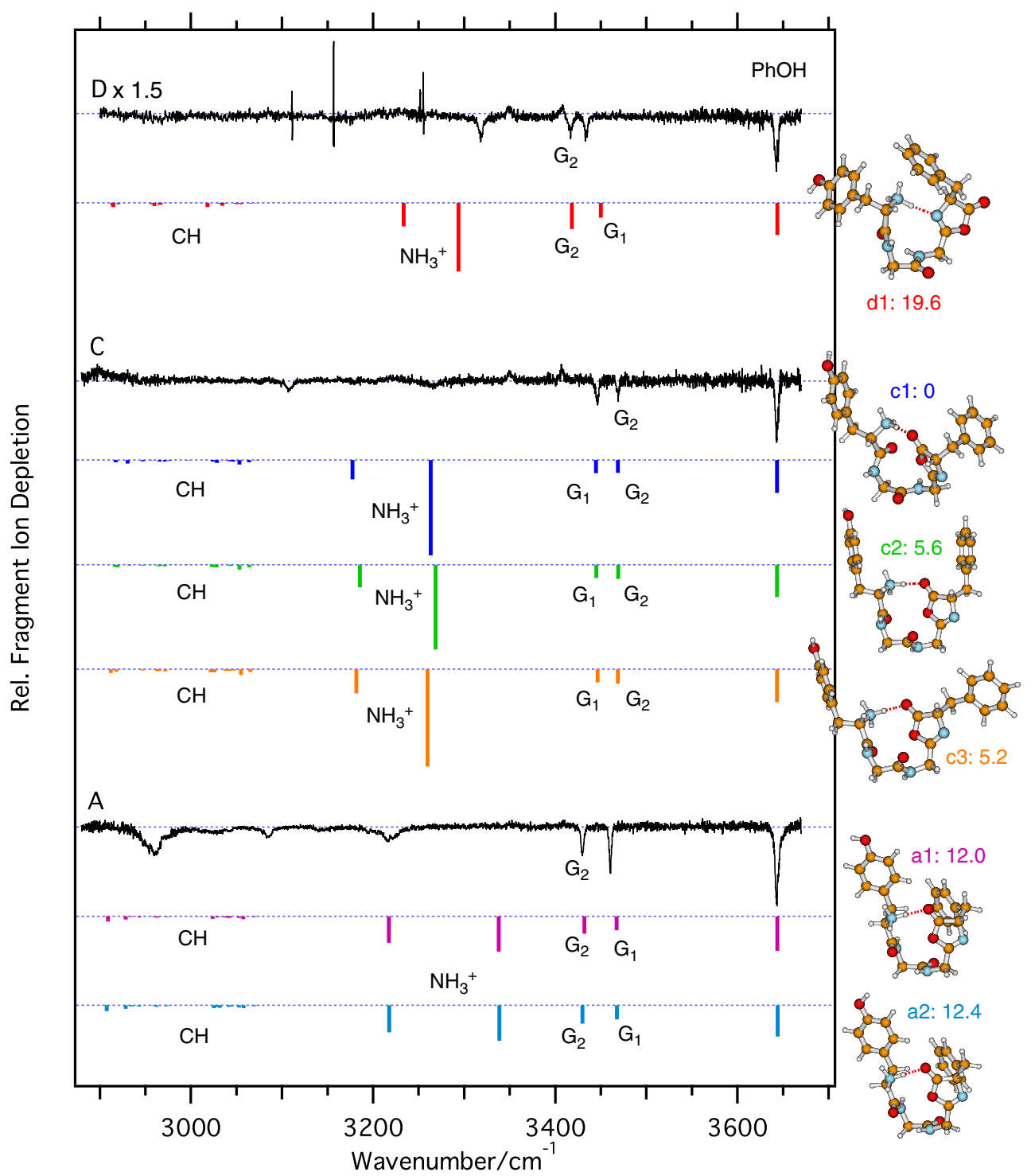

Figure 6. Comparison of IR-UV double resonance spectra of the $b_{4}$ conformers $A, C$, and D (relative intensity of D scaled by 1.5 , all monitoring the $[M+H-91]^{+}$fragment ion) to selected theoretical predictions $(B 3 L Y P / 6-31+G(d, p))$. Conformational structures and relative energies $/ \mathrm{kJ} \mathrm{mol}^{-1}$ (including harmonic zero point energy correction) are shown next to the corresponding traces. Note that structures $\mathrm{c} 1$ and $\mathrm{d} 1$ correspond to the structures $\mathrm{B}$ and $\mathrm{E}$ in References [34, 35], $\mathrm{c} 1$ has the lowest energy in the DFT calculations, also with respect to cyclic and oxazolone protonated isomers from References [34, 35] 
second glycine residue (G2) at the correct relative position (i.e., as the lower wavenumber amide $\mathrm{NH}$ vibration for conformers $\mathrm{A}$ and $\mathrm{D}$, and the opposite for conformer $\mathrm{C}$ ). A comparison for conformer $\mathrm{A}$ in the fingerprint region with the same structures is included in the Supplementary Material (Figure S3). Structures a1 and a2 differ mainly in the orientation of the tyrosine $\mathrm{OH}$ group only. None of the 39 calculated N-terminally protonated oxazolone structures resulted in acceptable agreement for the amide $\mathrm{NH}$ vibrations of conformer B.

From the comparison of the theoretical predictions to the experimental data we can deduce some trends that influence the appearance of the vibrational spectrum. The scaled $\mathrm{OH}$ vibration of the tyrosine side chain is for all structures predicted at 3643-3644 $\mathrm{cm}^{-1}$, in good agreement with the measured band position at $3643 \mathrm{~cm}^{-1}$ for all conformers in the experimental spectra. The $\mathrm{OH}$ group does not participate in hydrogen bonding. Due to its localized character, it is not a sensitive probe for the conformation of the fragment ions.

According to the experimental spectra, all three NHs of the protonated N-terminal ammonium group should be hydrogen-bonded with different hydrogen-bond strength for conformers $\mathrm{A}$ and $\mathrm{C}$. The structures a1, a2, c1, c2, and c3 from the calculations show a corresponding geometry in which one of the NHs is strongly hydrogen-bonded to the oxazolone carbonyl group, the second $\mathrm{NH}$ is bound to the tyrosine carbonyl group, and the third $\mathrm{NH}$ is oriented towards the aromatic $\pi$ system of the tyrosine side chain. However, the DFT calculations show deficiencies in predicting the hydrogen bond strengths correctly. While the red shift of the $\mathrm{NH}$ bound to the oxazolone $\mathrm{CO}$ is strongly overestimated (in all cases with scaled wavenumbers below $2870 \mathrm{~cm}^{-1}$, not shown in Figure 6), the other two NHs are predicted with too high wavenumbers (a1 and a2: $3338 \mathrm{~cm}^{-1}$ and $3218 \mathrm{~cm}^{-1}$ for the tyrosine CO bound and the $\pi$ bonded NHs compared with $3218 \mathrm{~cm}^{-1}$ and $3084 \mathrm{~cm}^{-1}$ measured for conformer A; c1: $3263 \mathrm{~cm}^{-1}$ and $3177 \mathrm{~cm}^{-1}, \mathrm{c} 2: 3269 \mathrm{~cm}^{-1}$ and $3186 \mathrm{~cm}^{-1}$, and $\mathrm{c} 3: 3260 \mathrm{~cm}^{-1}$ and $3182 \mathrm{~cm}^{-1}$ for the tyrosine $\mathrm{CO}$ bound and the $\pi$ bonded NHs compared with $3222 \mathrm{~cm}^{-1}$ and $3082 \mathrm{~cm}^{-1}$ measured for conformer C). In correspondence with an overestimation of the interaction of the $\mathrm{NH}_{3}{ }^{+}$group with the oxazolone carbonyl group, the position of the oxazolone $\mathrm{C}=\mathrm{O}$ stretching vibration in the fingerprint region is predicted too low for a1 and a2 with respect to the experimental spectrum of conformer A $\left(1770 \mathrm{~cm}^{-1}\right.$ compared with $1791 \mathrm{~cm}^{-1}$ in the experiment, see Figure S3). Because of a similar NH-OC interaction in structures $\mathrm{c} 1, \mathrm{c} 2$, and $\mathrm{c} 3$, their oxazolone $\mathrm{CO}$ vibrations are predicted at similar positions $\left(1764-1771 \mathrm{~cm}^{-1}\right)$. When this interaction is absent, the oxazolone $\mathrm{CO}$ vibration is shifted to higher wavenumbers (e.g., structure d1: $1884 \mathrm{~cm}^{-1}$ ).

The problems of the DFT calculations in predicting the pattern for the $\mathrm{NH}_{3}{ }^{+}$vibrations could originate in the same deficiencies that were encountered in the case of the $b_{2}$ and the $b_{3}$ ions and for protonated tyrosine and phenylalanine [48]. An underestimation of the $\mathrm{NH}-\pi$ interaction and overestimation of the $\mathrm{NH}-\mathrm{OC}$ interaction resulted in a mismatch of the vibrational pattern for the ammonium group. By analogy, we would need to conclude that an overestimation of the hydrogen-bond strength of the ammonium group with the oxazolone carbonyl group results in an underestimation of the interactions with the tyrosine carbon$\mathrm{yl}$ group and the aromatic $\pi$ system in the $b_{4}$ ions. Under this assumption and on the basis of the similarity of the ammonium $\mathrm{NH}$ stretching and the oxazolone carbonyl stretching vibrations of conformer B with conformer A, we can deduce a similar orientation and hydrogen-bonding pattern of the ammonium group in conformer B.

Conformer D shows a signal at a position that corresponds to a rather free or only weakly hydrogenbonded ammonium NH group. Structure d1 in Figure 6 shows a band that is predicted slightly red shifted with respect to the experimental position (d1: $3293 \mathrm{~cm}^{-1}$, conformer D: $3319 \mathrm{~cm}^{-1}$ ). However, as the geometrical structure indicates a hydrogen-bond interaction with the phenylalanine ring, the good correspondence is likely to arise from error-compensation.

Furthermore, we find a discrepancy for the prediction of the higher wavenumber amide $\mathrm{NH}$ vibration (d1 G1: $3450 \mathrm{~cm}^{-1}$, conformer D: $3434 \mathrm{~cm}^{-1}$ ), while the amide $\mathrm{NH}$ vibration of the second glycine residue (G2) is in good agreement (d1 G2: $3418 \mathrm{~cm}^{-1}$, conformer D G2: $3417 \mathrm{~cm}^{-1}$ ). In conclusion, structure $\mathrm{d} 1$ does not describe the orientation of the ammonium group and of the first glycine amide group in conformer D particularly well.

The predictions for the amide $\mathrm{NH}$ vibrations in structures $\mathrm{a} 1$, and $\mathrm{a} 2$, and in $\mathrm{c} 1, \mathrm{c} 2$, and $\mathrm{c} 3$ show a good correspondence with the observations for conformers $\mathrm{A}$ and $\mathrm{C}$. Their detailed positions are largely determined by the relative orientation to the carbonyl groups. The $\mathrm{NH}$ of the second glycine (G2) forms a hydrogen bond with the carbonyl group from the tyrosine residue. As this hydrogen bond closes a seven-membered ring, the molecule has certain flexibility for optimizing the interaction. The tyrosine carbonyl however acts as a hydrogen-bond acceptor to both the G2 NH and the ammonium group. The detailed balance between the two hydrogen bonds thus determines the exact position of the $\mathrm{G} 2$ and the corresponding ammonium $\mathrm{NH}$ vibration. In a1 and a2, the $\mathrm{G} 2 \mathrm{NH}-\mathrm{OC}$ hydrogen bond seems to be stronger than in $\mathrm{c} 1, \mathrm{c} 2$, and $\mathrm{c} 3$, and the $\mathrm{G} 2 \mathrm{NH}$ vibration thus appears at lower wavenumber $\left(3430 \mathrm{~cm}^{-1}\right.$ and $3432 \mathrm{~cm}^{-1}$, in good correspondence with the experimental position A: $3430 \mathrm{~cm}^{-1}$ ), whereas in $\mathrm{c} 1, \mathrm{c} 2$, and $\mathrm{c} 3$, the $\mathrm{G} 2$ $\mathrm{NH}-\mathrm{OC}$ hydrogen bond seems to be weaker than in a1 and $\mathrm{a} 2$, and the G2 $\mathrm{NH}$ appears at higher wavenumber (3469 $\mathrm{cm}^{-1}$, experimental C: $3469 \mathrm{~cm}^{-1}$ ). These trends are also reflected by the relative positions of the corresponding ammonium $\mathrm{NH}$ vibration, although their absolute position agrees less well with the measurements (vide supra). The $\mathrm{NH}$ of the first glycine residue (G1) can only interact with its own carbonyl group, and because of the proximity of the groups, there is a higher strain that restricts optimization of 
the orientation. The exact position of the G1 NH vibration is also influenced by the hydrogen bond between the $\mathrm{G} 2 \mathrm{NH}$ and the tyrosine $\mathrm{CO}$ : A stronger $\mathrm{G} 2 \mathrm{NH}$-tyrosine $\mathrm{CO}$ interaction, like in a1 and a2, leads to a less favorable orientation of the G1 NH relative to the G1 CO. Therefore, a1 and a2 show higher G1 NH wavenumbers $\left(3468 \mathrm{~cm}^{-1}\right.$ and $3467 \mathrm{~cm}^{-1}$, experimental A: $3461 \mathrm{~cm}^{-1}$ ). In $\mathrm{c} 1, \mathrm{c} 2$, and c3, where the two groups can come closer, the G1 NH vibration appears at lower wavenumber $\left(3445 \mathrm{~cm}^{-1}\right.$, $3445 \mathrm{~cm}^{-1}$, and $3446 \mathrm{~cm}^{-1}$, experimental C: $3446 \mathrm{~cm}^{-1}$ ).

The subtle balance between different intramolecular interactions leaves its fingerprint in the vibrational spectrum by influencing the exact positions of the vibrational bands in the XH stretching region. We identified structures that can largely explain important features in the measured spectra for conformers $\mathrm{A}$ and $\mathrm{C}$, while some deficiencies remain for conformer D. We could not yet identify a structure that would explain the spectrum of conformer B. However, on the basis of the trends identified from the other conformers, we can derive some constraints. The ammonium vibrations of conformer B appear at positions comparable to those of conformer A, which implies the presence of intramolecular interactions with similar bond strength. This could be a sign of similar orientations of the interacting groups in the conformer. The G2 amide NH vibration appears at slightly lower wavenumbers than in conformer A, which suggests a slightly stronger hydrogen bond for this group. The other amide NH (possibly G1), on the other hand, is strongly redshifted with respect to the other conformers. We therefore conclude that the G1 NH is engaged in a stronger hydrogen bond with a different acceptor than the other conformers. Additional calculations are needed to further elucidate this.

The population ratios between the different conformations that we observe can be influenced by storing the ions in the octopole for a short period prior to their injection into the 22-pole trap. For efficient pre-trapping in the octopole, $\mathrm{He}$ gas needs to be injected. The pre-trapping leaves more time for the ions to isomerize, and collisions with the room temperature gas can deliver sufficient energy to overcome certain isomerization barriers. The corresponding changes in relative UV peak intensities are illustrated in Figure S4 of the Supplementary Material.

It is clearly seen that the relative intensities of UV peaks that we assign to conformer A decrease with respect to those of conformer B upon pre-trapping, which implies an isomerization reaction of conformer A to B upon collisions with $\mathrm{He}$ and storage in the octopole. The situation is, however, not as clear for the other conformers, $\mathrm{C}$ and $\mathrm{D}$, as their lower UV peak intensities make relative intensity changes more difficult to identify. We do not observe new bands arise that cannot be assigned on the basis of the conformers A, B, C, and D, however, which means that pretrapping only induces conformational isomerization but does not change the chemical species. These observations might suggest that conformer $\mathrm{A}$ is a metastable conformer that is formed directly after the fragmentation event, which can relax to a more stable conformation B upon activation. Extracting reliable fractional populations from these measurements would be possible using laser population transfer techniques $[69,70]$, but these were beyond the scope of this work. Such experiments could also provide limits to isomerization barrier heights and are thus particularly interesting for more detailed experimental investigation of the potential energy surface of peptide fragment ions in the future.

The $a_{4}$ Ion On the basis of IRMPD and IMS measurements, it was previously concluded that the $a_{4}$ ion is formed as a mixture of several isomers [29, 35]. A major rearrangement that leads to a transfer of the phenylalanine side chain of the $\mathrm{C}$-terminal residue to the $\mathrm{N}$-terminal side of the molecule (see Scheme 2) has only recently been confirmed from theoretical calculations and IRMPD spectroscopy $[5,56]$. A corresponding cyclization/rearrangement pathway resulting in an amide structure has recently also been confirmed for $a_{5}$ ions [25], and cyclization reactions were proposed [71] and confirmed [40] for smaller $a$-type fragments before as well.

We show the UV photofragmentation spectrum of the $a_{4}$ ion from YGGFL that we measure in the region of the phenylalanine chromophore in Figure S1 (Supplementary Material) and the spectrum in the region of the tyrosine chromophore in Figure 1. From these spectra, we identify two isomers, with electronic band origins at $35179 \mathrm{~cm}^{-1}$ and $35238 \mathrm{~cm}^{-1}$, and progressions in vibrational modes of approximately $20 \mathrm{~cm}^{-1}$ (A and B) and $24 \mathrm{~cm}^{-1}$ (A) in the tyrosine region.

We show the vibrational spectra of these two isomers in Figure 7 (see also Table S4 in the Supplementary Material). The great similarity of these spectra suggests that we are observing only one chemical structure with two different conformations. While the band positions are very similar in the amide $\mathrm{NH}$ stretch region (A: $3549 \mathrm{~cm}^{-1}, 3439 \mathrm{~cm}^{-1}$, $3426 \mathrm{~cm}^{-1}$; B: $3548 \mathrm{~cm}^{-1}, 3438 \mathrm{~cm}^{-1}, 3429 \mathrm{~cm}^{1}$ ), larger differences are found at lower wavenumbers, where strongly hydrogen-bonded $\mathrm{NH}$ groups and the protonation sites are detected together with $\mathrm{CH}$ stretch vibrations (A: $3178 \mathrm{~cm}^{-1}$, $3092 \mathrm{~cm}^{-1}, 3050 \mathrm{~cm}^{-1}$; B: $3267 \mathrm{~cm}^{-1}, 3239 \mathrm{~cm}^{-1}, 3224 \mathrm{~cm}^{-1}$, $\left.3189 \mathrm{~cm}^{-1}\right)$.

We test the hypothesis of a rearrangement reaction by isotopic substitution of the phenylalanine nitrogen in YGGFL. In the rearranged structure, we should observe the asymmetric and symmetric stretching vibrations of the $\mathrm{NH}_{2}$ group that contains this nitrogen. Upon ${ }^{15} \mathrm{~N}$ labeling of this single nitrogen, two NH bands display a red shift in both conformers. The bands at $3549 \mathrm{~cm}^{-1}$ (conformer A) and $3548 \mathrm{~cm}^{-1}$ (B) shift by approximately $11 \mathrm{~cm}^{-1}$, and the bands at $3439 \mathrm{~cm}^{-1}$ (A) and $3438 \mathrm{~cm}^{-1}$ (B) shift by approximately $6 \mathrm{~cm}^{-1}$. These values correspond to the expectations for asymmetric and symmetric $\mathrm{NH}_{2}$ stretching vibrations, and are thus a proof that the amide nitrogen, which comes from the phenylalanine residue, forms a 


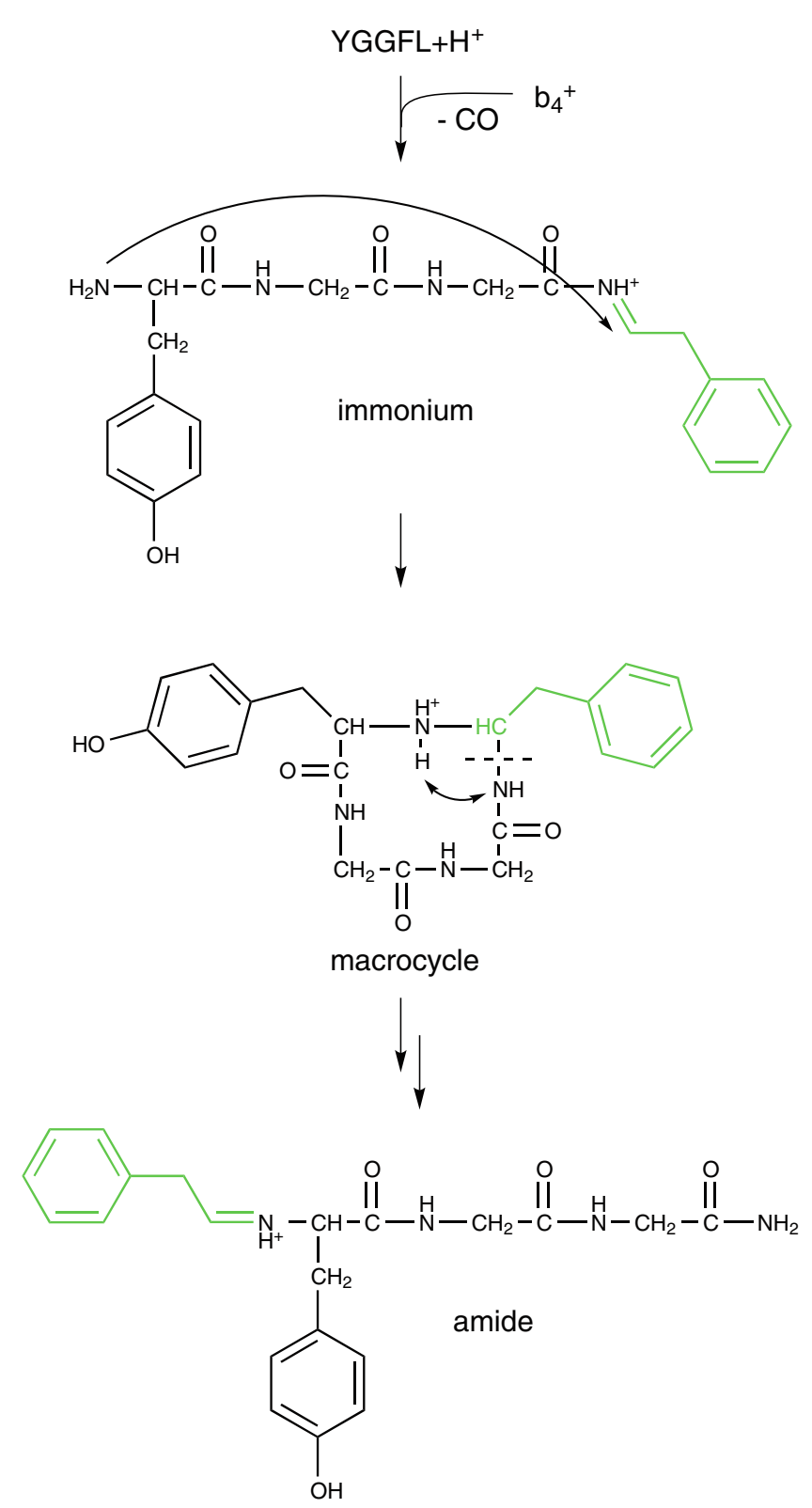

Scheme 2. Rearrangement reaction of YGGFL $a_{4}$ ions [5, 56]. The $a_{4}$ ion is initially formed with an immonium structure directly from protonated YGGFL or from the $b_{4}$ ion through loss of CO [11, 12]. Nucleophilic attack of the $\mathrm{N}$-terminal nitrogen on the immonium results in the formation of a macrocylce, which after proton transfer opens up at the phenylalanine $\mathrm{C}-\mathrm{N}$ bond. In the final amide structure, the phenylalanine side chain (marked in green) is transferred from the $\mathrm{C}$-terminal to the $\mathrm{N}$-terminal side of the molecule

free $\mathrm{NH}_{2}$ group in the $a_{4}$ ion. When we additionally exchange the nitrogen atom of the second glycine residue against ${ }^{15} \mathrm{~N}$, the third band in the amide region (A: $3426 \mathrm{~cm}^{-1}, \mathrm{~B}: 3429 \mathrm{~cm}^{-1}$ ) shows a $9 \mathrm{~cm}^{-1}$ isotopic red shift, indicative of an amide $\mathrm{NH}$ group. We can thus also confidently assign this $\mathrm{NH}$ in the spectra.

The $\mathrm{NH}$ vibration that originates in the other glycine residue is more elusive in the vibrational spectra and we

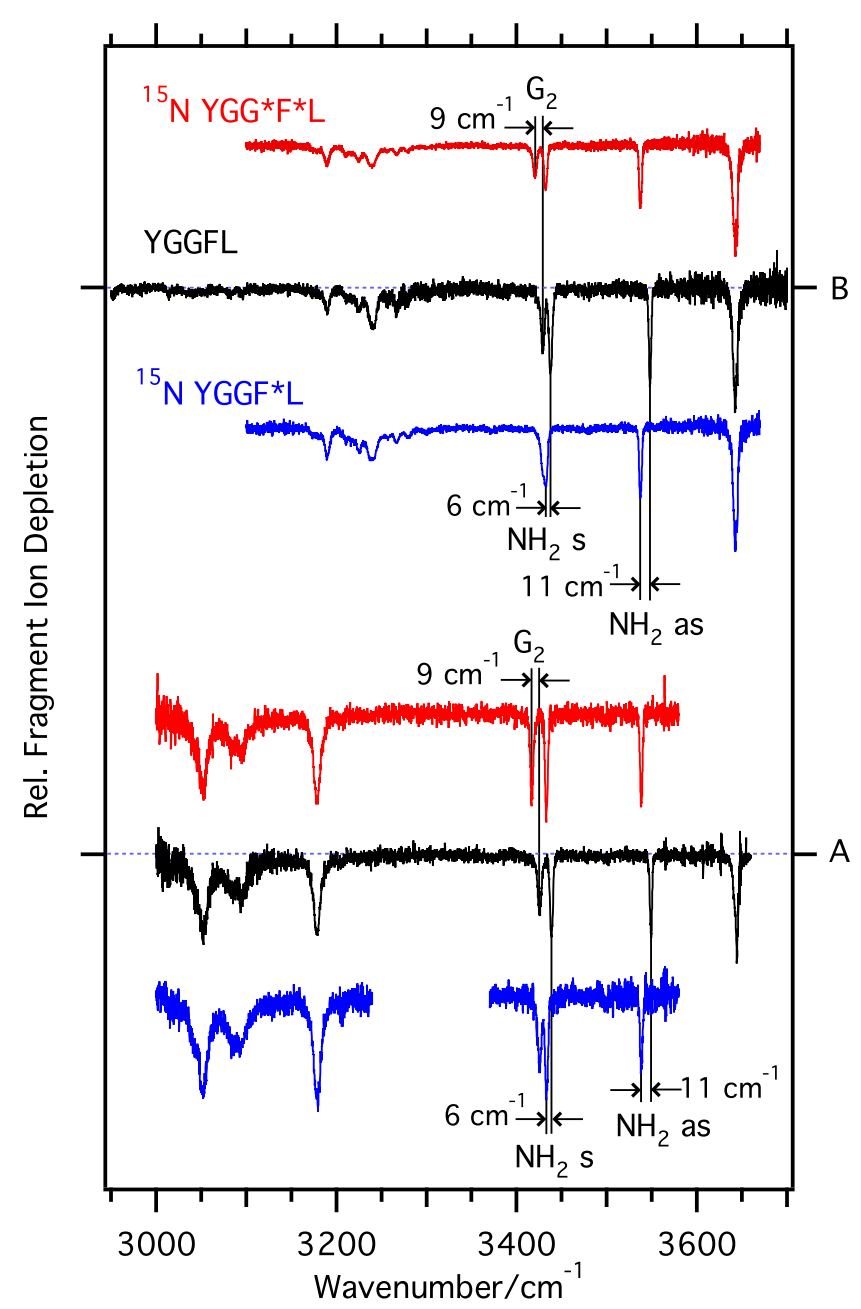

Figure 7. Conformation-selective IR-UV depletion spectra of the two isomers $\mathrm{A}$ and $\mathrm{B}$ of YGGFL $a_{4}$ ions (monitoring the $[\mathrm{M}+\mathrm{H}-91]^{+}$fragment ion). Isotopologues derived from ${ }^{15} \mathrm{~N}$ YGGF* (below, blue traces) and $Y G G^{*} F^{\star} L$ (above, red traces) are shown next to the spectra of the normal species (black traces). Isotopic red shifts are marked in the spectra together with corresponding assignments

cannot ultimately assign it from these experiments. Additional peaks are observed at lower wavenumbers where also the vibrations of the protonation site are expected, but further support from isotopic substitution would be required for a definitive assignment.

The spectra nevertheless provide strong support for the proposed rearrangement reaction $[5,56]$. In Figure 8, we compare them to theoretical predictions for rearranged isomers to obtain further information about the conformational structures. The shown structures represent the global minimum isomer from another study [56] (structure a) and two further rearranged conformations, which differ mainly in their orientation of the tyrosine $\mathrm{OH}$ group (structures $\mathrm{b}$ and $\mathrm{c}$ ).

The predictions reproduce the wavenumber difference between the $\mathrm{NH}_{2}$ symmetric stretching vibration and the G2 amide $\mathrm{NH}$ vibration that is observed for conformer A (a: $13 \mathrm{~cm}^{-1}$, b and c: $12 \mathrm{~cm}^{-1}$ compared with $\mathrm{A}: 13 \mathrm{~cm}^{-1}$ ), 


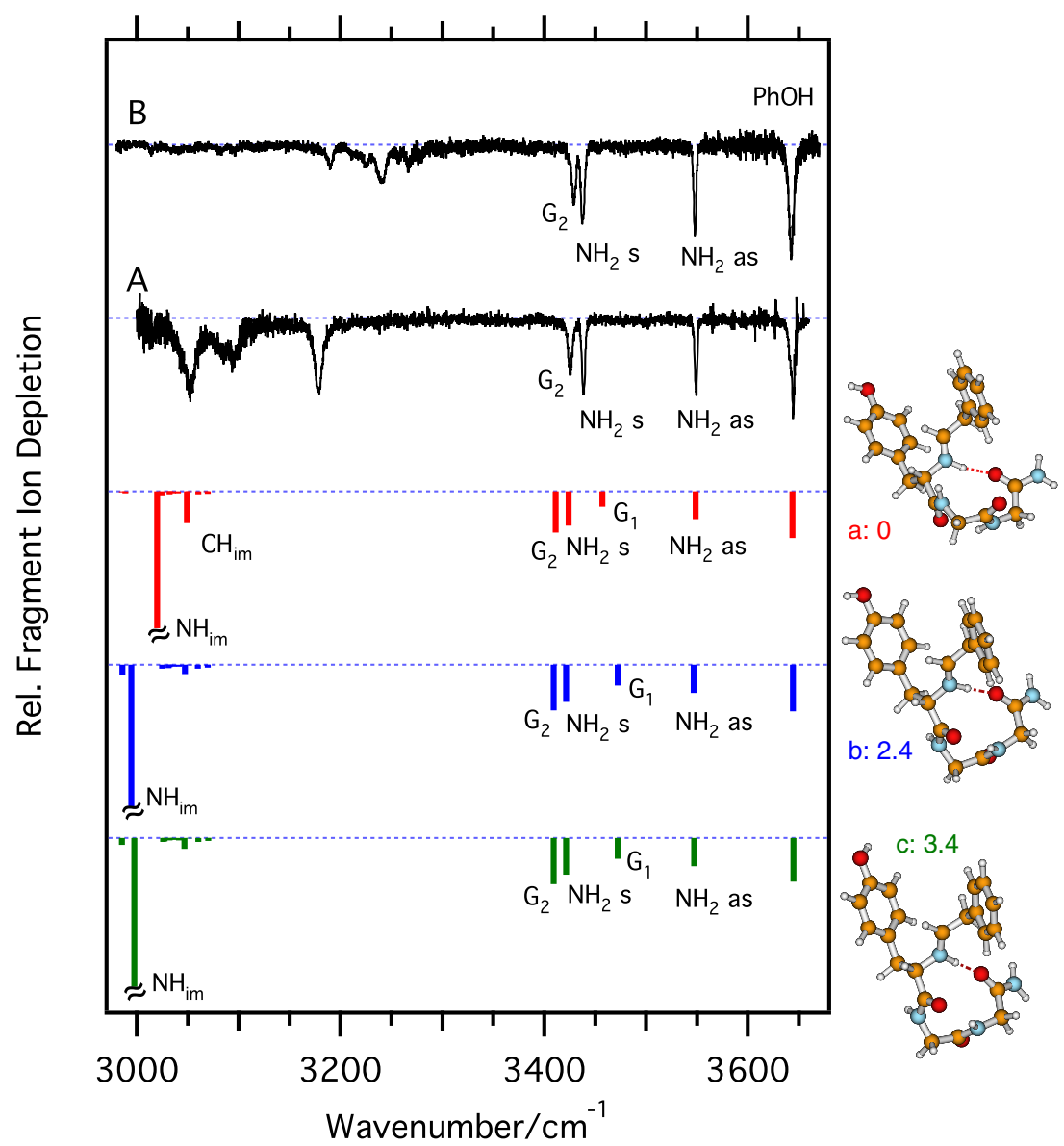

Figure 8. Comparison of the IR-UV double-resonance spectra of the $a_{4}$ ion to theoretical predictions (B3LYP/6-31+G(d,p)). Predicted intensities of the most intense vibration of the protonation sites; (a) $3020 \mathrm{~cm}^{-1}$, (b) $2995 \mathrm{~cm}^{-1}$, and (c) $2997 \mathrm{~cm}$ (bre truncated for better visibility of the lower intensity vibrations. Conformational structures and relative energies/kJ mol ${ }^{-1}$ (including harmonic zero point energy correction) are shown next to the corresponding traces

although the positions of these vibrations are predicted too low (a: $3424 \mathrm{~cm}^{-1}$ and $3411 \mathrm{~cm}^{-1}$, b: $3421 \mathrm{~cm}^{-1}$ and $3409 \mathrm{~cm}^{-1}$, c: $3422 \mathrm{~cm}^{-1}$ and $3410 \mathrm{~cm}^{-1}$, experimental: A: $3439 \mathrm{~cm}^{-1}$ and $3426 \mathrm{~cm}^{-1}$, B: $3438 \mathrm{~cm}^{-1}$ and $3429 \mathrm{~cm}^{-1}$ ). The smaller wavenumber difference between the $\mathrm{NH}_{2}$ symmetric stretching vibration and the $\mathrm{G} 2$ amide $\mathrm{NH}$ vibration in conformer $\mathrm{B}$ (approximately $9 \mathrm{~cm}^{-1}$ ) is not reproduced. The position of the asymmetric $\mathrm{NH}_{2}$ stretching vibration is well reproduced (a: $3549 \mathrm{~cm}^{-1}$, b: $3547 \mathrm{~cm}^{-1}$, c: $3547 \mathrm{~cm}^{-1}$ ), but seems to be a less sensitive probe of the structure. The same seems to be true for the $\mathrm{OH}$ stretching vibration. However, in some structures in which the $\mathrm{OH}$ group is hydrogen-bonded to the carbonyl group on the $\mathrm{C}$-terminal end of the molecule, this band can even be shifted below $3430 \mathrm{~cm}^{-1}$. As we can exclude such structures directly from the experimental data, we do not show them in Figure 8.

The G1 amide $\mathrm{NH}$ vibration is predicted at too high wavenumber, and we do not observe any vibration in the experimental spectra in close vicinity to the predictions (a: $3457 \mathrm{~cm}^{-1}$, b: $3472 \mathrm{~cm}^{-1}$, c: $3472 \mathrm{~cm}^{-1}$ ). At this point, we can only speculate as to whether the bands at $3178 \mathrm{~cm}^{-1}$ (A) and $3189 \mathrm{~cm}^{-1}$ (B) correspond to the $\mathrm{G} 1$ amide NH stretching vibrations. At the same time, it is interesting to note that the amide I vibration, which involves the carbonyl group from the same residue, is predicted too low (a: $1730 \mathrm{~cm}^{-1}$, b: $1731 \mathrm{~cm}^{-1}$, c: $1731 \mathrm{~cm}^{-1}$, compared with experimental values of A: $1766 \mathrm{~cm}^{-1}, \mathrm{~B}: 1758 \mathrm{~cm}^{-1}$, see Figure S5 and Table S4 in the Supplementary Material). This can be seen as a hint that the conformation is not yet well described, in particular with respect to this residue.

The predictions for the other amide I vibrations and the $\mathrm{C}=\mathrm{N}$ stretching vibration show a smaller red shift with respect to the experimentally observed bands in this range (experiment: A: $1723 \mathrm{~cm}^{-1}, 1710 \mathrm{~cm}^{-1}$, and $1703 \mathrm{~cm}^{-1}$; B: $1724 \mathrm{~cm}^{-1}$, $1712 \mathrm{~cm}^{-1}$, and $1705 \mathrm{~cm}^{-1}$; theory: $\mathrm{C}=\mathrm{N}: 1688 \mathrm{~cm}^{-1}$ (a), $1708 \mathrm{~cm}^{-1}$ (b), $1708 \mathrm{~cm}^{-1}$ (c); amide I: $1716 \mathrm{~cm}^{-1}, 1693 \mathrm{~cm}^{-1}$ (a), $1698 \mathrm{~cm}^{-1}, 1686 \mathrm{~cm}^{-1}$ (b), $1698 \mathrm{~cm}^{-1}, 1686 \mathrm{~cm}^{-1}$ (c).

From the isotopic shifts in the fingerprint region, we can identify the bending vibration of the $\mathrm{NH}_{2}$ group at $1613 \mathrm{~cm}^{-1}$ (A) and $1611 \mathrm{~cm}^{-1}$ (B) and the amide II vibration that involves the $\mathrm{G} 2 \mathrm{NH}$ group at $1526 \mathrm{~cm}^{-1}$ (A) and $1530 \mathrm{~cm}^{-1}$ (B), which are well predicted in calculations (a: $1607 \mathrm{~cm}^{-1}$ and $1536 \mathrm{~cm}^{-1}$, b: $1605 \mathrm{~cm}^{-1}$ and $1534 \mathrm{~cm}^{-1}$, c: $1605 \mathrm{~cm}^{-1}$ and $1534 \mathrm{~cm}^{-1}$ ). 
Some disagreement is found for the predictions of the vibrations of the protonation site in the $\mathrm{XH}$ stretching range. All calculated structures a, b, and c have a hydrogen bond between the $\mathrm{N}$-terminal immonium $\mathrm{NH}$ group and the carbonyl group originating from the G2 residue. The overestimation of the red shift of the corresponding $\mathrm{NH}$ vibration [predicted at $3020 \mathrm{~cm}^{-1}$ (a), $2995 \mathrm{~cm}^{-1}$ (b), and $2997 \mathrm{~cm}^{-1}$ (c)] implies that the interaction strength is overestimated. The $\mathrm{CH}$ group, which is attached to the immonium NH group, seems to form a weak hydrogen bond to the tyrosine aromatic ring, which is probably again underestimated in the DFT calculations. While under these assumptions such an arrangement might apply to the structure of conformer $\mathrm{A}$, the band pattern looks completely different for conformer B. This suggests a different orientation of this group in conformer B.

Further calculations are needed to unravel the detailed conformation of the two observed $a_{4}$ conformers $\mathrm{A}$ and $\mathrm{B}$. From the experimental side, these can be supported by further isotopic substitution experiments in which the nitrogen atoms of the tyrosine and/or the first glycine residues are substituted by ${ }^{15} \mathrm{~N}$. From such experiments, we should be able to assign the $\mathrm{NH}$ stretching vibrations that originate in these residues and thus provide corresponding constraints for the calculations. However, the experiments already lead to an assignment of the chemical structure of the $a_{4}$ ion, which supports the hypothesis of a rearrangement reaction through a cyclic intermediate $[5,56]$.

\section{Conclusions and Outlook}

This study presents the first application of UV photofragment spectroscopy and selective IR-UV double resonance in a low temperature ion trap to the structural investigation of peptide fragment ions. The chemical structures of $b$ - and $a$ type fragment ions formed from leucine-enkephalin were investigated. The selectivity of the double-resonance approach provides a powerful tool for individual spectroscopic characterization of different isomers of the fragment ions. In conjunction with selective isotopic labeling, the chemical structures of the different fragment ions were derived on the basis of the experiments alone.

Under the conditions applied in this work, the $b$-type fragments from leucine-enkephalin appear to favor oxazolone structures with protonation at the N-terminus. Macrocyclization reactions, which have been reported in room temperature infrared multiple photon dissociation spectroscopy experiments $[32,35]$, can be excluded under these conditions. On the other hand, a rearrangement reaction of the $a_{4}$ ion in which the phenylalanine side chain is transferred from the C-terminal to the $\mathrm{N}$-terminal side of the fragment ion through a macrocyclic intermediate $[5,56]$ was confirmed.

A closer comparison of isomer and conformer populations between different experimental approaches will become more important in the future to rationalize the conclusions between our work and previous studies.

The selective low-temperature spectroscopic data provide a particularly stringent test for theoretical methods, which are necessary to obtain information about the conformational arrangement of the fragment ions. The vibrational band positions, both in the $\mathrm{XH}$ stretching region and in the fingerprint region of the vibrational spectrum provide information about conformational details in the fragment ions such as hydrogen bonding patterns. At the low temperatures in the ion trap, low energy structures in the vicinity of the starting structure appear to be favored. Interconversion reactions over high barriers seem to be prohibited, even if they would lead to lower energy isomers. The method thus samples the low energy region of the potential surface in the vicinity of the starting structure after the fragmentation event.

Benchmark studies, as those reported here, will further profit from systematic investigations of different fragment ions of different sizes. For medium-sized fragments, the propensity for cyclization increases with the size of the fragment ions [20, 24, 26, 31, 32]. For small fragment ions, the presence of histidine appears to promote cyclization reactions $[20,39]$, while arginine seems to inhibit them [27, 28]. Nucleophilic side chain groups of certain amino acid residues may participate in ring-closing and ring-opening steps in fragmentation reactions [27, 72, 73]. Size- and sequence-dependent investigations thus promise to yield further insight into the fragmentation chemistry, and structural information derived from detailed and selective spectroscopic data will be particularly beneficial in this regard.

Simultaneous investigation of peptide fragment ions and cyclic peptides as well as fragments from acetylated peptide precursors can facilitate systematic comparison of cyclic and non-cyclic structures [44] and thus deliver experimental benchmark data that help to identify fingerprints for the different structures. The possibility to obtain single-photon absorption action spectra in different spectral regions in our approach promises to be particularly beneficial for generating such experimental benchmarks for the structural investigation of peptide fragment ions. The low temperature spectra also provide a basis for measuring experimental fractional populations from laser population transfer experiments [69, 70], which can furthermore enable measuring relative energies of isomers and isomerization barrier heights on the potential surface of peptide fragment ions.

\section{Acknowledgments}

The authors acknowledge support for this work by the École Polytechnique Fédérale de Lausanne and the Fonds National Suisse through grant 200020-130579. B.P. thanks the Deutsche Forschungsgemeinschaft (DFG) for a Heisenberg fellowship. 


\section{References}

1. Saminathan, I., Wang, X., Guo, Y., Krakovska, O., Voisin, S., Hopkinson, A., Siu, K.W.M.: The extent and effects of peptide sequence scrambling via formation of macrocyclic $b$ ions in model proteins. J. Am. Soc. Mass Spectrom. 21, 2085-2094 (2010)

2. Paizs, B., Suhai, S.: Fragmentation pathways of protonated peptides. Mass Spectrom. Rev. 24, 508-548 (2005)

3. Bleiholder, C., Osburn, S., Williams, T.D., Suhai, S., Van Stipdonk, M., Harrison, A.G., Paizs, B.: Sequence-scrambling fragmentation pathways of protonated peptides. J. Am. Chem. Soc. 130, 17774-17789 (2008)

4. Harrison, A.G., Young, A.B., Bleiholder, C., Suhai, S., Paizs, B.: Scrambling of sequence information in collision-induced dissociation of peptides. J. Am. Chem. Soc. 128, 10364-10365 (2006)

5. Bythell, B.J., Maitre, P., Paizs, B.: Cyclization and rearrangement reactions of a (n) fragment ions of protonated peptides. J. Am. Chem. Soc. 132, 14766-14779 (2010)

6. Vachet, R.W., Bishop, B.M., Erickson, B.W., Glish, G.L.: novel peptide dissociation: gas-phase intramolecular rearrangement of internal amino acid residues. J. Am. Chem. Soc. 119, 5481-5488 (1997)

7. Yu, L., Tan, Y.L., Tsai, Y., Goodlett, D.R., Polfer, N.C.: On the relevance of peptide sequence permutations in shotgun proteomics studies. J. Proteome Res. 10, 2409-2416 (2011)

8. Goloborodko, A., Gorshkov, M., Good, D., Zubarev, R.: Sequence scrambling in shotgun proteomics is negligible. J. Am. Soc. Mass Spectrom. 22, 1121-1124 (2011)

9. Paizs, B., Lendvay, G., Vekey, K., Suhai, S.: Formation of b(2)(+) ions from protonated peptides: an ab initio study. Rapid Commun. Mass Spectrom. 13, 525-533 (1999)

10. Paizs, B., Suhai, S.: Towards understanding the tandem mass spectra of protonated oligopeptides. 1: Mechanism of amide bond cleavage. J. Am Soc. Mass Spectrom. 15, 103-113 (2004)

11. Yalcin, T., Khouw, C., Csizmadia, I., Peterson, M., Harrison, A.: Why are B ions stable species in peptide spectra? J. Am. Soc. Mass Spectrom. 6, 1165-1174 (1995)

12. Yalcin, T., Csizmadia, I., Peterson, M., Harrison, A. The structure and fragmentation of $\mathrm{Bn}(\mathrm{n} \geq 3)$ ions in peptide spectra. J. Am. Soc. Mass Spectrom. 7, 233-242 (1996)

13. Polce, M.J., Ren, D., Wesdemiotis, C.: Dissociation of the peptide bond in protonated peptides. J. Mass Spectrom. 35, 1391-1398 (2000)

14. Allen, J.M., Racine, A.H., Berman, A.M., Johnson, J.S., Bythell, B.J., Paizs, B., Glish, G.L.: Why are a3 ions rarely observed? J. Am. Soc Mass Spectrom. 19, 1764-1770 (2008)

15. Bythell, B.J., Somogyi, A., Paizs, B.: What is the sStructure of b(2) ions generated from doubly protonated tryptic peptides? J. Am. Soc. Mass Spectrom. 20, 618-624 (2009)

16. Bythell, B.J., Suhai, S., Somogyi, A., Paizs, B.: Proton-driven amide bond-cleavage pathways of gas-phase peptide ions lacking mobile protons. J. Am. Chem. Soc. 131, 14057-14065 (2009)

17. Knapp-Mohammady, M., Young, A.B., Paizs, B., Harrison, A.G.: Fragmentation of doubly-protonated Pro-His-Xaa tripeptides: formation of b(2)(2+) Ions. J. Am. Soc. Mass Spectrom. 20, 2135-2143 (2009)

18. Bleiholder, C., Paizs, B.: Competing gas-phase fragmentation pathways of asparagine-, glutamine-, and lysine-containing protonated dipeptides. Theor. Chem. Acc. 125, 387-396 (2010)

19. Bythell, B.J., Csonka, I.P., Suhai, S., Barofsky, D.F., Paizs, B.: Gasphase structure and fragmentation pathways of singly protonated peptides with N-terminal arginine. J. Phys. Chem. B 114, 15092$15105(2010)$

20. Bythell, B.J., Knapp-Mohammady, M., Paizs, B., Harrison, A.G.: Effect of the His residue on the cyclization of b Ions. J. Am. Soc. Mass Spectrom. 21, 1352-1363 (2010)

21. Bleiholder, C., Suhai, S., Harrison, A.G., Paizs, B.: Towards understanding the tandem mass spectra of protonated oligopeptides. 2: The proline effect in collision-induced dissociation of protonated Ala-Ala-XxxPro-Ala $(\mathrm{Xxx}=$ Ala, Ser, Leu, Val, Phe, and Trp). J. Am. Soc. Mass Spectrom. 22, 1032-1039 (2011)

22. Gucinski, A., Somogyi, Á., Chamot-Rooke, J., Wysocki, V.: Separation and identification of structural isomers by quadrupole collision-induced dissociation-hydrogen/deuterium exchange-infrared multiphoton dissociation (QCID-HDX-IRMPD). J. Am. Soc. Mass Spectrom. 21, 1329$1338(2010)$

23. Harrison, A.G.: Peptide sequence scrambling through cyclization of $\mathrm{b} 5$ ions. J. Am. Soc. Mass Spectrom. 19, 1776-1780 (2008)
24. Harrison, A.G.: Cyclization of peptide b9 ions. J. Am. Soc. Mass Spectrom. 20, 2248-2253 (2009)

25. Harrison, A.G. Fragmentation Reactions of b5 and a5 ions containing proline: the structures of a5 ions. J. Am. Soc. Mass Spectrom. 23, 594-601 (2012)

26. Molesworth, S., Osburn, S., Van Stipdonk, M.: Influence of size on apparent scrambling of sequence during CID of b-type ions. J. Am. Soc. Mass Spectrom. 20, 2174-2181 (2009)

27. Molesworth, S., Osburn, S., Van Stipdonk, M.: Influence of amino acid side chains on apparent selective opening of cyclic b5 ions. J. Am. Soc. Mass Spectrom. 21, 1028-1036 (2010)

28. Molesworth, S., Van Stipdonk, M.: Apparent inhibition by arginine of macrocyclic $\mathrm{b}$ ion formation from singly charged protonated peptides. $J$. Am. Soc. Mass Spectrom. 21, 1322-1328 (2010)

29. Polfer, N.C., Bohrer, B.C., Plasencia, M.D., Paizs, B., Clemmer, D.E.: On the dynamics of fragment isomerization in collision-induced dissociation of peptides. J. Phys. Chem. A 112, 1286-1293 (2008)

30. Riba-Garcia, I., Giles, K., Bateman, R.H., Gaskell, S.J.: Evidence for structural variants of a- and b-type peptide fragment ions using combined ion mobility/mass spectrometry. J. Am. Soc. Mass Spectrom. 19, 609-613 (2008)

31. Chen, X., Yu, L., Steill, J.D., Oomens, J., Polfer, N.C.: Effect of peptide fragment size on the propensity of cyclization in collision-induced dissociation: oligoglycine b2-b8. J. Am. Chem. Soc. 131, 18272-18282 (2009)

32. Chen, X., Steill, J.D., Oomens, J., Polfer, N.C.: Oxazolone versus macrocycle structures for Leu-enkephalin b2-b4: insights from infrared multiple-photon dissociation spectroscopy and gas-phase hydrogen/deuterium exchange. J. Am. Soc. Mass Spectrom. 21, 1313-1321 (2010)

33. Verkerk, U.H., Zhao, J., Van Stipdonk, M.J., Bythell, B.J., Oomens, J., Hopkinson, A.C., Siu, K.W.M.: Structure of the $[\mathrm{M}+\mathrm{H}-\mathrm{H} 2 \mathrm{O}]^{+}$ion from tetraglycine: a revisit by means of density functional theory and isotope labeling. J. Phys. Chem. A 115, 6683-6687 (2011)

34. Polfer, N.C., Oomens, J., Suhai, S., Paizs, B.: Spectroscopic and theoretical evidence for oxazolone ring formation in collision-induced dissociation of peptides. J. Am. Chem. Soc. 127, 17154-17155 (2005)

35. Polfer, N.C., Oomens, J., Suhai, S., Paizs, B.: Infrared spectroscopy and theoretical studies on gas-phase protonated Leu-enkephalin and its fragments: Direct experimental evidence for the mobile proton. J. Am. Chem. Soc. 129, 5887-5897 (2007)

36. Yoon, S.H., Chamot-Rooke, J., Perkins, B.R., Hilderbrand, A.E., Poutsma, J.C., Wysocki, V.H.: IRMPD spectroscopy shows that AGG forms an oxazolone b2+ ion. J. Am. Chem. Soc. 130, 17644-17645 (2008)

37. Erlekam, U., Bythell, B.J., Scuderi, D., Van Stipdonk, M., Paizs, B., Maître, P.: Infrared spectroscopy of fragments of protonated peptides: direct evidence for macrocyclic structures of b5 ions. J. Am. Chem. Soc. 131, 11503-11508 (2009)

38. Oomens, J., Young, S., Molesworth, S., van Stipdonk, M.: Spectroscopic evidence for an oxazolone structure of the b2 fragment ion from protonated tri-alanine. J. Am. Soc. Mass Spectrom. 20, 334-339 (2009)

39. Perkins, B.R., Chamot-Rooke, J., Yoon, S.H., Gucinski, A.C., Somogyi, A., Wysocki, V.H.: Evidence of diketopiperazine and oxazolone structures for HA b2+ ion. J. Am. Chem. Soc. 131, 17528-17529 (2009)

40. Verkerk, U.H., Siu, C.-K., Steill, J.D., El Aribi, H., Zhao, J., Rodriquez, C.F., Oomens, J., Hopkinson, A.C., Siu, K.W.M.: a2 Ion Derived from Ttriglycine: an N1-protonated 4-imidazolidinone. J. Phys. Chem. Lett. 1, 868-872 (2010)

41. Sinha, R., Erlekam, U., Bythell, B., Paizs, B., Maître, P.: Diagnosing the protonation site of $\mathrm{b} 2$ peptide fragment ions using IRMPD in the $\mathrm{X}-$ $\mathrm{H}(\mathrm{X}=\mathrm{O}, \mathrm{N}$, and C) stretching region. J. Am. Soc. Mass Spectrom. 22, $1645-1650(2011)$

42. Wang, D., Gulyuz, K., Stedwell, C., Polfer, N.: Diagnostic NH and OH vibrations for oxazolone and diketopiperazine structures: b2 from protonated triglycine. J. Am. Soc. Mass Spectrom. 22, 1197-1203 (2011)

43. Polfer, N.C.: Infrared multiple photon dissociation spectroscopy of trapped ions. Chem. Soc. Rev. 40, 2211-2221 (2011)

44. Chen, X., Tirado, M., Steill, J.D., Oomens, J., Polfer, N.C.: Cyclic peptide as reference system for b ion structural analysis in the gas phase. J. Mass Spectrom. 46, 1011-1015 (2011)

45. Rizzo, T.R., Stearns, J.A., Boyarkin, O.V.: Spectroscopic studies of cold, gas-phase biomolecular ions. Int. Rev. Phys. Chem. 28, 481-515 (2009) 
46. Boyarkin, O.V., Mercier, S.R., Kamariotis, A., Rizzo, T.R.: Electronic spectroscopy of cold, protonated tryptophan and tyrosine. J. Am. Chem. Soc. 128, 2816-2817 (2006)

47. Mercier, S.R., Boyarkin, O.V., Kamariotis, A., Guglielmi, M., Tavernelli, I., Cascella, M., Rothlisberger, U., Rizzo, T.R.: Microsolvation effects on the excited-state dynamics of protonated tryptophan. J. Am. Chem. Soc. 128, 16938-16943 (2006)

48. Stearns, J.A., Mercier, S., Seaiby, C., Guidi, M., Boyarkin, O.V., Rizzo, T.R.: Conformation-specific spectroscopy and photodissociation of cold, protonated tyrosine and phenylalanine. J. Am. Chem. Soc. 129, 11814-11820 (2007)

49. Stearns, J.A., Guidi, M., Boyarkin, O.V., Rizzo, T.R.: Conformationspecific infrared and ultraviolet spectroscopy of tyrosine-based protonated dipeptides. J. Chem. Phys. 127, 154322-154327 (2007)

50. Stearns, J.A., Boyarkin, O.V., Rizzo, T.R.: Spectroscopic signatures of gas-phase helices: Ac-Phe-(Ala)5-Lys-H+ and Ac-Phe-(Ala)10-Lys-H+ . J. Am. Chem. Soc. 129, 13820-13821 (2007)

51. Stearns, J.A., Seaiby, C., Boyarkin, O.V., Rizzo, T.R.: Spectroscopy and conformational preferences of gas-phase helices. Phys. Chem. Chem. Phys. 11, 125-132 (2009)

52. Nagornova, N.S., Rizzo, T.R., Boyarkin, O.V.: Highly resolved spectra of gas-phase gramicidin S: a benchmark for peptide structure calculations. J. Am. Chem. Soc. 132, 4040-4041 (2010)

53. Nagornova, N.S., Guglielmi, M., Doemer, M., Tavernelli, I., Rothlisberger, U., Rizzo, T.R., Boyarkin, O.V.: Cold-ion spectroscopy reveals the intrinsic structure of a decapeptide. Angew. Chem. Int. Ed. 50, 5383-5386 (2011)

54. Sztáray, J., Memboeuf, A., Drahos, L., Vékey, K.: Leucine enkephalin - a mass spectrometry standard. Mass Spectrom. Rev. 30, 298-320 (2011)

55. Bythell, B.J., Erlekam, U., Paizs, B., Maitre, P.: Infrared spectroscopy of fragments from doubly protonated tryptic peptides. Chem. Phys. Chem. 10, 883-885 (2009)

56. Paizs, B.; Bythell, B.J.; Maître, P. Rearrangement pathways of the a4 ion of protonated YGGFL characterized by IR spectroscopy and modeling. Manuscript in preparation 2012.

57. Svendsen, A., Lorenz, U.J., Boyarkin, O.V., Rizzo, T.R.: A new tandem mass spectrometer for photofragment spectroscopy of cold, gas-phase molecular ions. Rev. Sci. Instrum. 81, 073107 (2010)

58. Gerlich, D.: Experimental investigations of ion-molecule reactions relevant to interstellar chemistry. J. Chem. Soc. Faraday Trans. 89, 2199-2208 (1993)

59. Gerlich, D.: Ion-neutral collisions in a 22-pole trap at very low energies. Phys. Scr. 199(5), 256 (1995)

60. Gerlich, D.: Inhomogeneous RF fields: a versatile tool for the study of processes with slow ions. Adv. Chem. Phys. 82, 1 (2007)

61. Case, D.A.P.; Perlman, D. A.; Caldwell, J.W.; Cheatham T.E. III; Ross, W.S.; Simmerling, C.L.; Darden, T.A.; Merz, K.M.; Stanton, R.V.; Cheng, A.L.; Vincent, J.J.; Crowley, M.; Tsui, V.; Radmer, R.J.; Duan, Y.; Pitera, J.; Massova, I.G.; Seibel, G.L.; Singh, U.C.; Weiner, P.K.; Kollmann, P.A., AMBER 99. 1999: University of California: San Francisco.

62. Frisch, M.J., Trucks, G.W., Schlegel, H.B., Scuseria, G.E., Robb, M.A., Cheeseman, J.R., Montgomery Jr., J.A., Vreven, T., Kudin, K.N., Burant, J.C., Millam, J.M., Iyengar, S.S., Tomasi, J., Barone, V., Mennucci, B., Cossi, M., Scalmani, G., Rega, N., Petersson, G.A., Nakatsuji, H., Hada, M., Ehara, M., Toyota, K., Fukuda, R., Hasegawa, J., Ishida, M., Nakajima, T., Honda, Y., Kitao, O., Nakai, H., Klene, M., Li, X., Knox, J.E., Hratchian, H.P., Cross, J.B., Adamo, C., Jaramillo, J., Gomperts, R., Stratmann, R.E., Yazyev, O., Austin, A.J., Cammi, R., Pomelli, C., Ochterski, J.W., Ayala, P.Y., Morokuma, K., Voth, G.A.,
Salvador, P., Dannenberg, J.J., Zakrzewski, V.G., Dapprich, S., Daniels, A.D., Strain, M.C., Farkas, O., Malick, D.K., Rabuck, A.D., Raghavachari, K., Foresman, J.B., Ortiz, J.V., Cui, Q., Baboul, A.G., Clifford, S., Cioslowski, J., Stefanov, B.B., Liu, G., Liashenko, A., Piskorz, P., Komaromi, I., Martin, R.L., Fox, D.J., Keith, T., Al-Laham, M.A., Peng, C.Y., Nanayakkara, A., Challacombe, M., Gill, P.M.W., Johnson, B., Chen, W., Wong, M.W., Gonzalez, C., Pople, J.A.: Gaussian 03, Revision C.02. Gaussian Inc., Wallingford CT (2004)

63. Frisch, M.J., Trucks, G.W., Schlegel, H.B., Scuseria, G.E., Robb, M.A., Cheeseman, J.R., Scalmani, G., Barone, V., Mennucci, B., Petersson, G.A., Nakatsuji, H., Caricato, M., Li, X., Hratchian, H.P., Izmaylov, A.F., Bloino, J., Zheng, G., Sonnenberg, J.L., Hada, M., Ehara, M., Toyota, K., Fukuda, R., Hasegawa, J., Ishida, M., Nakajima, T., Honda, Y., Kitao, O., Nakai, H., Vreven, T., Montgomery Jr., J.A., Peralta, J.E., Ogliaro, F., Bearpark, M., Heyd, J.J., Brothers, E., Kudin, K.N., Staroverov, V.N., Kobayashi, R., Normand, J., Raghavachari, K., Rendell, A., Burant, J.C., Iyengar, S.S., Tomasi, J., Cossi, M., Rega, N., Millam, J.M., Klene, M., Knox, J.E., Cross, J.B., Bakken, V., Adamo, C., Jaramillo, J., Gomperts, R., Stratmann, R.E., Yazyev, O., Austin, A.J., Cammi, R., Pomelli, C., Ochterski, J.W., Martin, R.L., Morokuma, K., Zakrzewski, V.G., Voth, G.A., Salvador, P., Dannenberg, J.J., Dapprich, S., Daniels, A.D., Farkas, O., Foresman, J.B., Ortiz, J.V., Cioslowski, J., Fox, D.J.: Gaussian 09, Revision A.02. Gaussian, Inc., Wallingford CT (2009)

64. Kang, H., Jouvet, C., Dedonder-Lardeux, C., Martrenchard, S., Gregoire, G., Desfrancois, C., Schermann, J.P., Barat, M., Fayeton, J.A.: Ultrafast deactivation mechanisms of protonated aromatic amino acids following UV excitation. Phys. Chem. Chem. Phys. 7, 394-398 (2005)

65. Cordero, M.M., Houser, J.J., Wesdemiotis, C.: The neutral products formed during backbone fragmentations of protonated peptides in tandem mass-spectrometry. Anal. Chem. 65, 15941601 (1993)

66. Paizs, B., Suhai, S.: Combined quantum chemical and RRKM modeling of the main fragmentation pathways of protonated GGG. I. Cis-trans isomerization around protonated amide bonds. Rapid Commun. Mass Spectrom. 15, 2307-2323 (2001)

67. Harrison, A.G.: To $b$ or not to $b$ : The ongoing saga of peptide $b$ ions. Mass Spectrom. Rev. 28, 640-654 (2009)

68. Paizs, B., Suhai, S.: Combined quantum chemical and RRKM modeling of the main fragmentation pathways of protonated GGG. II. Formation of $b(2)$, y(1), and y(2) ions. Rapid Commun. Mass Spectrom. 16, 375-389 (2002)

69. Dian, B.C., Longarte, A., Zwier, T.S.: Conformational dynamics in a dipeptide after single-mode vibrational excitation. Science 296, 2369$2373(2002)$

70. Zwier, T.S.: Laser probes of conformational isomerization in flexible molecules and complexes. J. Phys. Chem. A 110, 4133-4150 (2006)

71. Aribi, H.E., Rodriquez, C.F., Almeida, D.R.P., Ling, Y., Mak, W.W.N., Hopkinson, A.C., Siu, K.W.M.: Elucidation of fragmentation mechanisms of protonated peptide ions and their products: a case study on glycylglycylglycine using density functional theory and threshold collision-induced dissociation. J. Am. Chem. Soc. 125, 9229-9236 (2003)

72. Farrugia, J.M., O'Hair, R.A.J., Reid, G.E.: Do all b2 ions have oxazolone structures? Multistage mass spectrometry and ab initio studies on protonated $\mathrm{N}$-acyl amino acid methyl ester model systems. Int. J. Mass Spectrom. 210/211, 71-87 (2001)

73. Farrugia, J.M., Taverner, T., O'Hair, R.A.J.: Side-chain involvement in the fragmentation reactions of the protonated methyl esters of histidine and its peptides. Int. J. Mass Spectrom. 209, 99-112 (2001) 